\title{
Wake Characteristics of Tall Buildings in a Realistic Urban Canopy
}

\author{
Denise Hertwig $^{1}$ (D) Hannah L. Gough ${ }^{1}$ (D) - Sue Grimmond ${ }^{1}$ (D) Janet F. Barlow ${ }^{1}$ (D) \\ Christoph W. Kent ${ }^{1}$ (D) William E. Lin ${ }^{2}$ (D) Alan G. Robins ${ }^{2} \cdot$ Paul Hayden $^{2}$
}

Received: 17 November 2018 / Accepted: 2 April 2019 / Published online: 19 April 2019

(c) The Author(s) 2019

\begin{abstract}
The presence of tall buildings in cities affects momentum and scalar exchange within and above the urban canopy. As wake effects can be important over large distances, they are crucial for urban-flow modelling on and across different spatial scales. We explore the aerodynamic effects of tall buildings on the microscale to local scales with a focus on the interaction between the wake structure, canopy and roughness sublayer flow of the surroundings in a realistic urban setting in central London. Flow experiments in a boundary-layer wind tunnel use a 1:200 scale model with two tall buildings $(81 \mathrm{~m}$ and $134.3 \mathrm{~m})$ for two wind directions. Large changes in mean flow, turbulence statistics and instantaneous flow structure of the wake are evident when tall buildings are part of the complex urban canopy rather than isolated. In the near-wake, the presence of lower buildings displaces the core of the recirculation zone upwards, thereby reducing the vertical depth over which flow reversal occurs. This amplifies vertical shear at the rooftop and enhances turbulent momentum exchange. In the near part of the main wake, lateral velocity fluctuations and hence turbulence kinetic energy are reduced compared to the isolated building case as eddies generated in the urban canopy and roughness sublayer distribute energy down to smaller scales that dissipate more rapidly. Evaluation of a wake model for flow past isolated buildings suggests model refinements are needed to account for such flow-structure changes in tall-building canopies.
\end{abstract}

Keywords Tall-building environments · Urban canopy · Urban flow · Wake model · Wind tunnel

\section{Nomenclature}

$H \quad$ Building (roof) height

$H_{\text {NoTall }} \quad$ Mean building height (No Tall)

$H_{\text {ave }} \quad$ Mean building height

Electronic supplementary material The online version of this article (https://doi.org/10.1007/s10546-01900450-7) contains supplementary material, which is available to authorized users.

Denise Hertwig

d.hertwig@reading.ac.uk

1 Department of Meteorology, University of Reading, P.O. Box 243, Reading RG6 6BB, UK

2 EnFlo, Department of Mechanical Engineering Sciences, University of Surrey, Guildford GU2 7XH, UK 


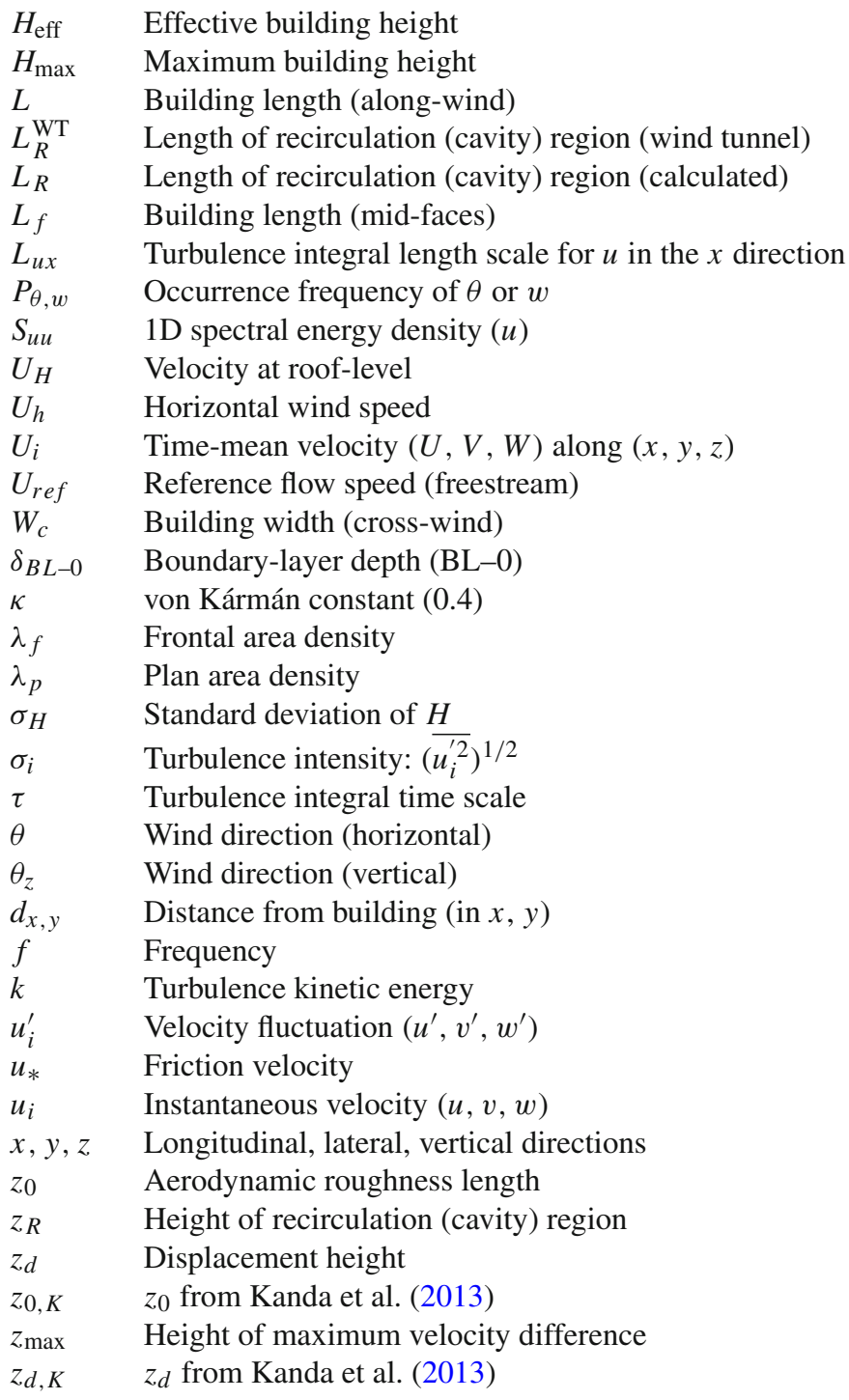

\section{ADMS-Build model}

$\begin{array}{ll}\ell_{y, z} & \text { Cross-wind length scales } \\ \eta, \xi & \text { Normalized } y, z \text { coordinates } \\ \hat{u} & \text { Velocity perturbation } \\ D_{y}, D_{z} & \text { Eddy viscosities } \\ g(\xi), h(\eta) & \text { Shape functions } \\ x_{0} & \text { Virtual origin }\end{array}$

\section{Acronyms}

BL-0 Boundary layer upwind of model

ISL Inertial sublayer

LDA Laser Doppler anemometry 


$\begin{array}{ll}\text { MOST } & \text { Monin-Obukhov similarity theory } \\ \text { RSL } & \text { Roughness sublayer } \\ \text { TKE } & \text { Turbulence kinetic energy } \\ \text { UCL } & \text { Urban canopy layer } \\ \mathrm{T}_{134} & \text { Tall building; } H=134 \mathrm{~m} \\ \mathrm{~T}_{81} & \text { Tall building; } H=81 \mathrm{~m}\end{array}$

\section{Introduction}

With increasing urban populations, cities worldwide are growing upward and outward, with tall buildings, in isolation or as clusters, introducing complex flow interactions across scales. Aerodynamic, thermal and radiative processes are altered locally and downwind, as are the strength and distribution of anthropogenic emissions of heat, pollutants and moisture. Such modifications induced by tall buildings and the interaction with the surrounding low-rise neighbourhoods have implications for a number of urban environmental stresses, such as wind comfort (e.g. Xu et al. 2017), heat (e.g. Yang et al. 2010; Yang and Li 2015), and pollutant dispersion and street-canyon ventilation (Brixey et al. 2009; Heist et al. 2009; Fuka et al. 2018). All of these aspects challenge the general applicability of current urban-modelling concepts in high-rise cities at the local scale and mesoscale (Barlow et al. 2017).

Conceptual modelling frameworks used in micrometeorology typically treat urban processes as a two-dimensional (2D) problem. This ranges from the representation of cities in land-surface models as slabs or infinitely long uniform street canyons (Masson 2000; Coceal and Belcher 2004; Grimmond et al. 2010), to the classic categorization of street-canyon flow according to the ratio of building height to street width into skimming, wake interference or isolated roughness regimes (Hussain and Lee 1980; Oke 1988).

Prevailing modelling concepts based on Monin-Obukhov similarity theory (MOST) require the calculation of variables at levels well above both the urban canopy layer (UCL) and the urban roughness sublayer (RSL), plus the presence of a fully-developed inertial sublayer (ISL). If (very) tall buildings protrude deep into the urban boundary layer, such requirements are unlikely to be met in either the vertical or horizontal scales of interest, making MOST-based modelling even more questionable over cities. Hence, there is a need to extend current modelling frameworks to account for processes in the vertical. However, to do this, a better understanding of critical processes in tall-building environments is required.

Studies of tall-building aerodynamics (mostly for isolated structures) to a large degree are driven by the wind-engineering community's interest in defining building design standards (Kwon and Kareem 2013; Holmes 2014), related to pedestrian wind comfort and safety (Blocken and Carmeliet 2004; Tominaga et al. 2008; Blocken et al. 2012) and/or urban ventilation ( $\mathrm{Ng}$ 2009). Studies on wind loads and wind comfort for isolated buildings have been concerned either with existing structures (e.g. Wardlaw and Moss 1970; Li et al. 2006, 2007), idealized cuboidal obstacles (Lim et al. 2009) and recently also with towers of various realistic shapes ( $\mathrm{Xu}$ et al. 2017). The fact that flow around tall buildings in realistic urban environments may be considerably different from isolated-building cases is not usually addressed.

While the impact of the surroundings on tall buildings has been investigated previously (e.g. Daniels et al. 2013; Elshaer et al. 2016; Le and Caracoglia 2016), the effect of a tall building's wake on low-lying surroundings and on the overall structure of the downwind urban boundary layer is still not well explored. Heist et al. (2009) and Fuka et al. (2018) 
showed that tall buildings in idealized street systems considerably affect the street-canyon flow. The downward flow on the windward face of the tall building intensifies the vortex in the upwind street canyon and outflow from this street is enhanced (horizontal flow divergence). The large pressure deficit on the leeward side of the tall building results in horizontal flow convergence and strong updrafts in the downwind street canyon.

Accounting for wake effects of buildings, whether high-rise or low-rise, is essential in modelling urban dispersion. Different models have been developed to capture the flow characteristics in the two distinct regions of the building wake: the recirculation zone in the near-wake and the momentum-deficit region of the main wake (Appendix 1, Fig. 12). Corresponding changes in pollutant pathways (downwards and inwards deflection) and turbulent mixing need to be parametrized.

Examples are the velocity-deficit parametrization based on a shelter-model approach used in the QUIC-Urb model (Pardyjak et al. 2004; Singh et al. 2006); the small-deficit wake model based on constant eddy-viscosity theory implemented in the ADMS-Build model (Robins and McHugh 2001; Robins et al. 2018) described in Appendix 1, or the building downwash algorithm used in the AERMOD-Prime model (Petersen et al. 2017). These models are based on the empirical and theoretical understanding of flow around isolated, cuboid buildings of low aspect ratios $\left(H / \sqrt{W_{c} L}\right)$ of building height $(H)$ to cross-wind width $\left(W_{c}\right)$ and alongwind length $(L)$, for which the wake flow changes in response to the turbulence intensity of the inflow (e.g. Castro and Robins 1977). However, it is unclear whether the wake responds in a similar way for tall buildings with large aspect ratios and in the presence of a low-level urban canopy.

In the present study we explore the aerodynamic effects of tall buildings and the interaction of their wakes with RSL and UCL turbulence on the microscale to local scales in a realistic model of an area of central London (Fig. 1). The objectives are to investigate the impact of: (i) building-height heterogeneity on flow within and above the UCL, (ii) tall-building wakes on flow in the surrounding neighbourhood, and (iii) building-height variability and presence of tall buildings for urban flow modelling.

For this case study, we used a boundary-layer wind tunnel to generate flow data for different morphometric settings (building heights/densities):

1. Urban canopy with and without tall buildings;

2. Tall buildings in isolation;

3. Tall buildings surrounded by buildings of increased heights.

Effects on mean flow, turbulence and the instantaneous flow structure are investigated as a function of the longitudinal and lateral range of influence of tall-building wakes within and above the canopy. Measurements are compared with the ADMS-Build wake model to identify model limitations.

\section{Wind-Tunnel Model}

Wind-tunnel experiments were conducted at the Environmental Flow (EnFlo) Research Centre, University of Surrey, using the EPSRC MAGIC project (www.magic-air.uk) model domain and scale model (Song et al. 2018). With a test-section length of $20 \mathrm{~m}$ and a crosssection of $3.5 \mathrm{~m} \times 1.5 \mathrm{~m}$, the wind tunnel is one of the largest facilities in Europe dedicated to the investigation of urban flow and dispersion phenomena. 

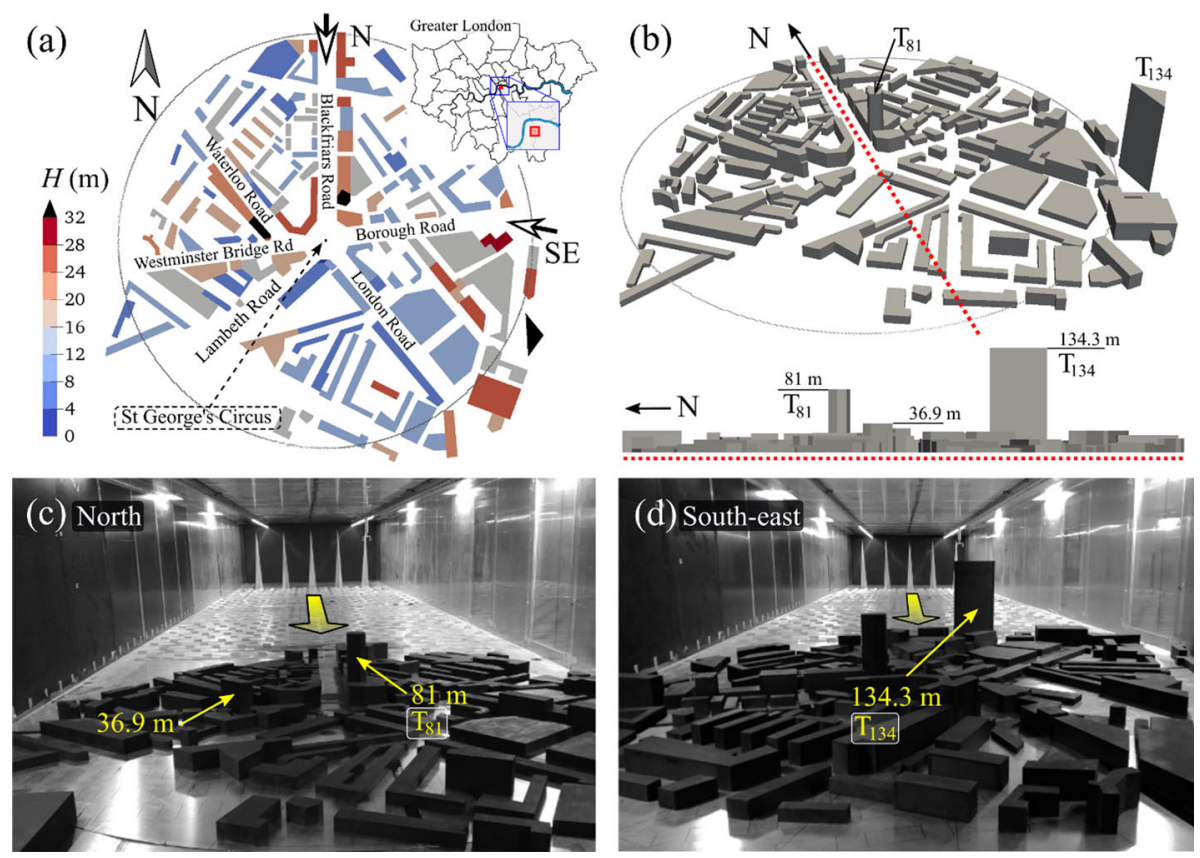

Fig. 1 a Full-scale building heights for main buildings in the wind-tunnel model with the two forcing wind directions from north $\left(\mathrm{N} ; 0^{\circ}\right)$ and south-east $\left(\mathrm{SE} ; 101^{\circ}\right)$. The three tallest buildings $(H>32 \mathrm{~m})$ are drawn in black. Circle indicates the turntable (700 m-diameter full scale). b Model in the horizontal plane (3D; upper panel) and vertical cross-section along the north-south axis (2D; lower panel). c North and d south-east view of the model in the wind tunnel in its core configuration. Triangular vortex generators and floor roughness elements can be seen upwind of the model. The three tallest buildings are indicated

\subsection{South London Model Domain}

The model domain extends approximately $700 \mathrm{~m}$ around St George's Circus $\left(51.4987^{\circ} \mathrm{N}\right.$, $0.1048^{\circ} \mathrm{W}$; WGS84 datum) in the London Borough of Southwark (Fig. 1a). Of the 148 buildings in the model area, $49 \%$ are low-rise residential (building height $H \leq 12 \mathrm{~m}$ ), $39 \%$ are mid-rise office and commercial $(12 \mathrm{~m}<H \leq 24 \mathrm{~m})$ and only 17 exceed $24 \mathrm{~m}$. Of those, three are taller than $32 \mathrm{~m}\left(2.2 H_{\text {ave }}\right.$ with $H_{\text {ave }}=14.7 \mathrm{~m}$ as the mean block height based on all 148 buildings in the model). The tallest building ( $\mathrm{T}_{134}$; triangular footprint), with a height of $H_{134}=134.3 \mathrm{~m}$, is located at the south-eastern edge of the domain (Fig. 1b). The second tallest building ( $\mathrm{T}_{81} ; H_{81}=81 \mathrm{~m}$; hexagonal footprint) is located close to the model centre. The third tallest $(H=36.9 \mathrm{~m})$, located west of St George's Circus, is much shorter.

\subsection{Model Characteristics}

The main building structures in the domain were reproduced at a scale of 1:200, sufficient to allow both canopy-layer flow structure and tall-building wakes to be measured. Model buildings are based on Ordnance Survey GIS data $(2014,2016)$ plus information on current (2017) construction. The full-scale accuracy of these data is approximately $1 \mathrm{~m}$. Buildings are represented by idealized blocks, without small-scale façade details or courtyards. All model buildings have flat roofs, corresponding to the height of the eaves. No other urban features (e.g. vegetation, bus shelters) are included in the model. 
The central part of the model was mounted on a $3.48 \mathrm{~m}$-diameter turntable $(\approx 700 \mathrm{~m}$ in full scale), allowing model orientations to be modified for different mean forcing wind directions. The St George's Circus intersection at the model centre (Fig. 1a) is located $14 \mathrm{~m}$ downwind of the tunnel inlet.

Building outlines drawn onto the tunnel floor facilitated positioning. Model buildings were not fixed to the turntable, permitting different geometric configurations to be readily installed. Some buildings at the edge of the model domain, off the turntable, are aligned manually with the aid of laser light sheets (Sect. 3.2 for alignment uncertainties). Both the wooden buildings and parts of the turntable at the measurement sites were painted black to reduce laser reflections from the optical measurement equipment (Sect. 3).

Two principal wind directions investigated are: north (N, $0^{\circ}$; Fig. 1c) and (east-)south-east (SE, $101^{\circ}$; Fig. 1d). In both, the model spans the entire width of the tunnel. Building $\mathrm{T}_{134}$ is removed in the north configuration when the focus is on building $\mathrm{T}_{81}$ due to tunnel limitations, while both are present in the south-east orientation. Geometrical parameters of the two tall buildings by wind direction (Table 1$)$ consist of cross-wind widths $\left(W_{c, 81}, W_{c, 134}\right)$, alongwind building lengths defined by the distance between the points furthest upwind/downwind $\left(L_{81}, L_{134}\right)$ and along-wind projection between the centres of the furthest upwind/downwind building faces $\left(L_{f, 81}, L_{f, 134}\right)$. The $L_{f}$ length definition is used in the ADMS-Build model (Robins et al. 2018). For the triangular $\mathrm{T}_{134}$ tower, $L_{f, 134}$ is based on the projection between the upwind building corner and the centre of the downwind face. The $H / \sqrt{W_{c} L}$ ratios for both buildings are large: 3.6 ( $\mathrm{T}_{81}$, north orientation) and $5.7\left(\mathrm{~T}_{134}\right.$, south-east) with $L=L_{f}$.

\subsubsection{Geometry Configurations}

Four geometry configurations are defined:

1. Core: All buildings included (Fig. 2a, d).

2. No Tall: Tall buildings $(H>32 \mathrm{~m})$ removed (Fig. $2 \mathrm{~b}, \mathrm{e})$.

3. Tall: All buildings with $H<32 \mathrm{~m}$ removed, except for the MAGIC target building $(H=9 \mathrm{~m})$ in the model centre (Fig. 2c, f).

4. Increased: As the Core case, but with the heights of five buildings downwind of tower $\mathrm{T}_{134}$ increased to $\approx 30 \mathrm{~m}$; south-east orientation only (Fig. $2 \mathrm{~g}$ ).

These cases allow the study of interactions between the low-rise urban canopy and wakes of tall buildings by isolating the effects of the tall buildings (Tall cases) and the low-rise

Table 1 Full-scale geometry parameters $(\mathrm{m})$ of the two tallest buildings $\mathrm{T}_{81}$ (north/south-east model orientations) and $\mathrm{T}_{134}$ (south-east only)

\begin{tabular}{lllll}
\hline Flow direction & Parameter & & $\mathrm{T}_{81}$ & $\mathrm{~T}_{134}$ \\
\hline \multirow{3}{*}{ North } & Height & $H$ & 81.0 & 134.3 \\
& Cross-wind width & $W_{c}$ & 22.82 & - \\
& Along-wind length & $L$ & 28.09 & - \\
\multirow{3}{*}{ South-east } & Along-wind length (mid-face) & $L_{f}$ & 21.16 & - \\
& Cross-wind width & $W_{c}$ & 26.21 & 71.65 \\
& Along-wind length & $L$ & 23.7 & 18.51 \\
& Along-wind length (mid-face) & $L_{f}$ & 21.47 & 27.86 \\
\hline
\end{tabular}



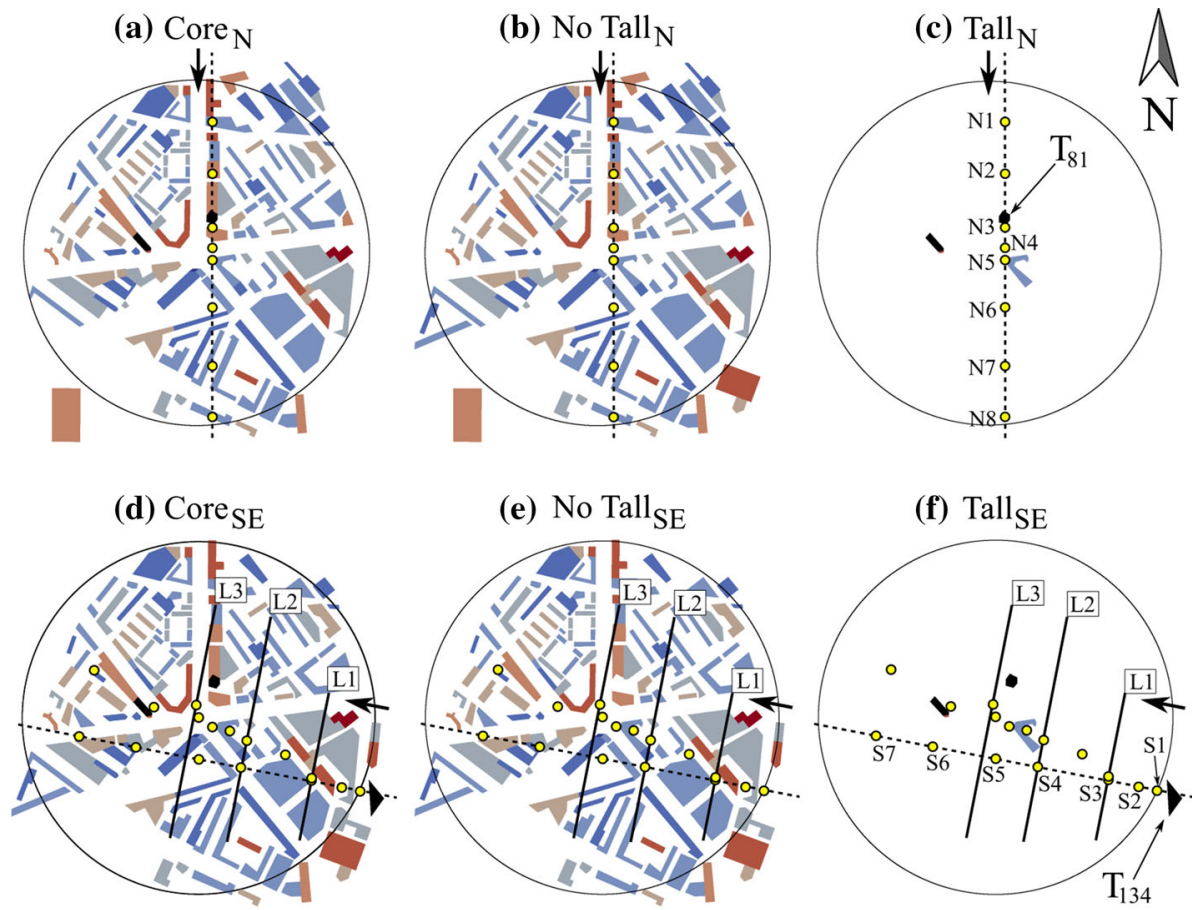

(g) Increased $\mathrm{SE}$
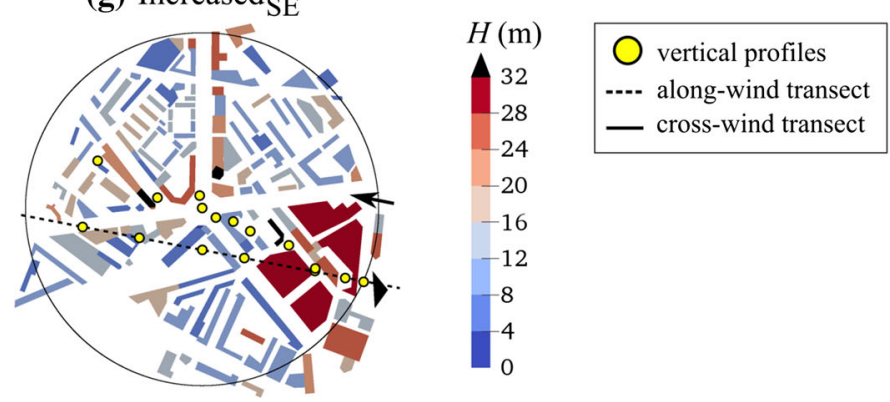

Fig. 2 Wind-tunnel geometries and measurement sites for $\mathbf{a}-\mathbf{c}$ north $(\mathrm{N})$ and $\mathbf{d}-\mathbf{g}$ south-east (SE) model orientations. Building heights $(H)$ are given in full scale; structures taller than $32 \mathrm{~m}$ are drawn in black. Turntable extent (large circle) and forcing wind direction (arrow) are indicated. The longitudinal $x$-axis of the flow coordinate system is always aligned with the approach-flow wind direction

canopy (No Tall cases) before combining them (Core cases). The Increased case (south-east configuration) is designed to test whether raising the roof-level of buildings within the nearwake of a tall building has any notable effects on the flow fields downwind. Shaped foam blocks were placed underneath the wooden buildings to increase their heights by factors of 2 or 3 (approximately $30 \mathrm{~m}$ roof-level).

Building heights and measurement locations are shown in Fig. 2. Depending on site and measurement mode (Sect. 3.1), vertical flow profiles contained up to 20 points between a minimum full-scale height of $4.5 \mathrm{~m}$ and a maximum of $126 \mathrm{~m}(U-V$ mode) or $134.3 \mathrm{~m}$ ( $U-W$ mode). The measurement height is restricted by the tunnel height and the mounting 
of the traverse system holding the measuring probe. For tower $\mathrm{T}_{134}$ velocities could not be measured above roof-level, while for building $\mathrm{T}_{81}$ the highest measurement point is at $z / H_{81}=1.66$. For the south-east wind direction the $\mathrm{T}_{134}$ building is offset from the tunnel centreline (Fig. 1d). Possible impacts of this feature on the wake structure in terms of blocking effects are discussed in Sect. 4.3.

Time restrictions prevented repeat measurements at all sites in each configuration. Data available for all cases are at sites distributed over the entire extent of the model at various distances from the tall buildings (eight locations for north, 16 for south-east). Some sites lie on longitudinal (along-wind) transects through the principal tall buildings (see site codes in Fig. 2c, f). The longitudinal distances $\left(d_{x} / H\right)$ of these sites from the centres of the tall buildings are given in Table 2 . The along-wind transect behind building $\mathrm{T}_{134}$ is slightly offset from the building's centre by $d_{y} / H_{134}=0.07$ (9.4 $\mathrm{m}$ full scale).

For three south-east cases (Core SE, No Tall $_{\mathrm{SE}}$, Tall $\mathrm{SE}_{\mathrm{SE}}$ ) the wake structure behind building $\mathrm{T}_{134}$ was also measured on lateral (cross-wind) transects at three longitudinal distances from the building: $d_{x} / H_{134}=0.98$ (coinciding with site S3), 2.0 (S4) and 2.86, labelled L1, L2 and L3 (Fig. 2d). For each transect the flow was measured at four heights above the low-rise canopy: $z / H_{134}=0.2,0.48$ and $0.94(U-V$ mode $)$ or $1.0(U-W$ mode $)$.

\subsubsection{Morphometric and Roughness Characteristics}

Building height, morphometric and roughness parameters derived for the No Tall, Core and Increased cases (Table 3$)$ include: plan area density $\left(\lambda_{p}\right.$, ratio of plan area of buildings to the total plan area), frontal area density $\left(\lambda_{f}\right.$; ratio of vertical area exposed in the windward direction to the total plan area), average $\left(H_{\mathrm{ave}}\right)$ and maximum $\left(H_{\max }\right)$ building heights and standard deviation $\left(\sigma_{H}\right)$, displacement height $\left(z_{d, K}\right)$ and aerodynamic roughness length $\left(z_{0, K}\right)$. The latter two are calculated using the morphometric method by Kanda et al. (2013) (subscript ' $\mathrm{K}$ ') that directly incorporates the roughness-element height variability. The method has been found to provide good estimates compared to other morphometric approaches when assessed with anemometric data (Kent et al. 2017, 2018). The parameters in Table 3 are derived for each model area using a 500-m radius (full scale). Differences between north and south-east model configurations result from buildings being added or removed.

The triangular building $\mathrm{T}_{134}$ in the Core $\mathrm{SE}_{\mathrm{S}}$ set-up modifies $z_{d, K}$ and $z_{0, K}$ compared to the Core $_{\mathrm{N}}$ case (Fig. 2a, d) through an increase in $\sigma_{H}$. Increasing the heights of five buildings in

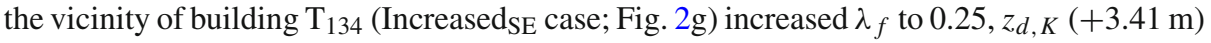
and $z_{0, K}(+0.3 \mathrm{~m})$ compared to Core $\mathrm{SE}$. Although roof heights were only raised to $30 \mathrm{~m}$ (i.e. ten-storey buildings) in a small sub-domain, the effect on the roughness parameters is large.

\section{Flow Experiments}

All flow experiments were conducted for neutral stability conditions. We use a Cartesian coordinate system aligned with the principal axes of the wind tunnel (i.e. with the approach flow), where $x, y, z$ denote longitudinal, lateral and vertical directions. The instantaneous velocity components along these directions are $u, v$, and $w$. Time-averaged quantities are written in uppercase, and taking the example of the longitudinal velocity component, $u=$ $U+u^{\prime}$, where $u^{\prime}$ is the fluctuation about the mean, $U$. 
Table 2 Longitudinal distances $d_{x} / H$ of sites on along-wind transects (codes in Fig. 2c, f) from the centre of buildings $\mathrm{T}_{81}$ (north orientation) and $\mathrm{T}_{134}$ (south-east)

\begin{tabular}{llllllllll}
\hline North & Site code & $\mathrm{N} 1$ & $\mathrm{~N} 2$ & $\mathrm{~N} 3$ & $\mathrm{~N} 4$ & $\mathrm{~N} 5$ & $\mathrm{~N} 6$ & $\mathrm{~N} 7$ & $\mathrm{~N} 8$ \\
& $d_{x} / H_{81}$ & -2.38 & -1.1 & 0.24 & 0.76 & 1.05 & 2.24 & 3.69 & 4.95 \\
& $d_{x} / W_{c, 81}$ & -8.45 & -3.9 & 0.85 & 2.7 & 3.73 & 7.95 & 13.1 & 17.57 \\
& $d_{x} / L_{81}$ & -6.86 & -3.17 & 0.69 & 2.19 & 3.03 & 6.46 & 10.64 & 14.27 \\
South-east & Site code & $\mathrm{S} 1$ & $\mathrm{~S} 2$ & $\mathrm{~S} 3$ & $\mathrm{~S} 4$ & $\mathrm{~S} 5$ & $\mathrm{~S} 6$ & $\mathrm{~S} 7$ & \\
& $d_{x} / H_{134}$ & 0.27 & 0.55 & 0.99 & 2.03 & 2.66 & 3.61 & 4.45 & \\
& $d_{x} / W_{c, 134}$ & 0.51 & 1.03 & 1.86 & 3.81 & 4.99 & 6.77 & 8.34 & \\
& $d_{x} / L_{134}$ & 1.96 & 3.99 & 7.18 & 14.73 & 19.3 & 26.19 & 32.3 & \\
\hline
\end{tabular}

Negative sign used for sites upwind of the tall building

Table 3 Building height $(\mathrm{m})$, morphometric and roughness $(\mathrm{m})$ parameters for each model configuration shown in Fig. 2

\begin{tabular}{lllllllc}
\hline Case & $z_{0, K}$ & $z_{d, K}$ & $\lambda_{p}$ & $\lambda_{f}$ & $H_{\text {ave }}$ & $H_{\max }$ & $\sigma_{H}$ \\
\hline No Tall $_{\mathrm{N}}$ & 0.87 & 17.99 & 0.35 & 0.21 & 13.18 & 30.4 & 5.89 \\
Core $_{\mathrm{N}}$ & 1.07 & 20.96 & 0.35 & 0.21 & 13.52 & 81.0 & 7.52 \\
Tall $_{\mathrm{N}}$ & - & - & - & - & - & 81.0 & - \\
No Tall $_{\text {SE }}$ & 0.98 & 18.39 & 0.34 & 0.21 & 13.51 & 30.4 & 6.20 \\
Core $_{\text {SE }}$ & 2.35 & 28.1 & 0.34 & 0.22 & 14.79 & 134.3 & 12.95 \\
Increased $_{\text {SE }}$ & 2.65 & 31.51 & 0.34 & 0.25 & 17.35 & 134.3 & 13.90 \\
Tall $_{\text {SE }}$ & - & - & - & - & - & 134.3 & - \\
\hline
\end{tabular}

Parameters are derived for a 500-m radius area around the model centre. Lengths are given in full scale

The coordinate system originates in the centre of the turntable, coinciding with the model centre (Fig. 1a).

\subsection{Velocity Measurements}

Single-point velocity time series were measured with a two-component Dantec laser Doppler anemometry (LDA) system using a FiberFlow probe with a diameter of $27 \mathrm{~mm}$ and a focal length of $160 \mathrm{~mm}$. The principal axis of the ellipsoidal LDA measuring volume (length: $1.57 \mathrm{~mm}$ ) is aligned with the vertical axis of the tunnel and the secondary axes lie in the horizontal plane (diameter: $0.074 \mathrm{~mm}$ ). These dimensions correspond to $0.3 \mathrm{~m}$ and $0.015 \mathrm{~m}$ in full scale.

Reflective $\mu \mathrm{m}$-sized sugar-water droplets were introduced into the flow at the tunnel inlet as seeding particles. In order to acquire signals of all three velocity components, the 2D LDA probe was operated both in the $U-V$ and $U-W$ orientations. A small mirror oriented at $45^{\circ}$ was used in the $U-W$ mode to reach measurement locations within street canyons. The LDA was mounted on a 3D automated traverse system covering the final $12 \mathrm{~m}$ of the test section. All equipment was controlled by bespoke 'virtual instrument' software. The ambient lab conditions were continuously monitored and logged.

For each sample, the tunnel freestream flow speed, $U_{\text {ref }}$, was measured using an ultrasonic anemometer at $1 \mathrm{~m}$ above the tunnel floor, $9 \mathrm{~m}$ upwind of the model centre $(7.3 \mathrm{~m}$ from the leading edge) and $5 \mathrm{~m}$ downwind of the tunnel inlet. This ensured that effects of the 
anemometer wake on flow within and above the model are negligible. The anemometer was offset from the tunnel centreline by $1 \mathrm{~m}$, but still located well outside the side-wall shear layer. Between individual measurements the recorded freestream flow speed differed by no more than $2 \%$ from the set value of $2 \mathrm{~m} \mathrm{~s}^{-1}$.

All measurements were undertaken only after the average seeding rate and freestream flow were given time to settle. The majority of velocity samples were taken over a duration of $120 \mathrm{~s}$. Taking into account the geometric scale reduction of the model (1:200), this corresponds to a full-scale sampling duration of $6 \mathrm{~h} 40 \mathrm{~min}$ at the same reference flow speed of $2 \mathrm{~m} \mathrm{~s}^{-1}$ (or $2 \mathrm{~h} 40 \mathrm{~min}$ at $5 \mathrm{~m} \mathrm{~s}^{-1}$ ). Sampling frequencies (LDA data rates) were typically of the order of $100 \mathrm{~Hz}$, but varied from site to site based on the local seeding conditions (lower data rates in sheltered flow regions in the canopy layer; higher in the RSL above the buildings). In some cases of low data rates longer measurement periods ( $240 \mathrm{~s}$ and $480 \mathrm{~s}$ ) were used to ensure a large enough sample size for statistical analyses.

All data analyzed have undergone quality-control checks with respect to measurement duration, data rates and spike occurrences for each individual time series. Further checks included comparisons of the $U$ and $\overline{u^{\prime 2}}$ statistics available from $U-V$ and $U-W$ measurements. Differences for these quantities were not allowed to be greater than 10 times the median standard error (Sect. 3.2). Since the use of a mirror can induce larger measurement uncertainties, data from the $U-W$ measurements were disregarded in all cases when this criterion was not met.

\subsection{Uncertainty Quantification}

Statistical errors are connected to the general stochastic variability of turbulent flows that leads to an unavoidable difference between the most likely flow state and velocity statistics determined over a finite averaging period from a single realization of the experiment (Wyngaard 1992). In our study we assess the inherent uncertainty statistically through the standard error for each velocity statistic. For the time-averaged velocities the median standard errors based on all samples taken within the different model configurations at all $x, y, z$ locations are approximately $1 \%(U), 11 \%(V)$ and $8.5 \%(W)$ of the mean. The corresponding values for the velocity variances are $7 \%\left(\overline{u^{\prime 2}}\right), 5.2 \%\left(\overline{v^{\prime 2}}\right)$ and $5 \%\left(\overline{w^{\prime 2}}\right)$. Velocity covariances on average have higher relative uncertainties of $14 \%\left(\overline{u^{\prime} w^{\prime}}\right)$ and $34 \%\left(\overline{u^{\prime} v^{\prime}}\right)$.

Systematic errors arise from uncertainties regarding the exact boundary conditions of the experiment and overall experimental uncertainty. We assess that the main sources are (lengths given in the wind-tunnel scale):

1. Overall accuracy of model buildings $( \pm 0.5 \mathrm{~mm})$.

2. Positioning uncertainty of the LDA probe relative to the buildings due to

- Horizontal positioning accuracy of model buildings ( $\pm 1-2 \mathrm{~mm})$. As buildings were manually moved on and off the turntable to configure the different test cases, accuracy may vary between runs.

- Variability of the elevation of the tunnel floor across the main test section $( \pm 1-2 \mathrm{~mm})$.

- Positioning accuracy relative to the buildings provided by the traverse system holding the LDA $( \pm 0.1 \mathrm{~mm})$.

- Alignment accuracy of the LDA measuring volume relative to the tunnel axes $\left( \pm 0.1^{\circ}\right)$.

- Orientation accuracy of the turntable with respect to the principal tunnel axis $\left( \pm 0.1^{\circ}\right)$, resulting in an uncertainty in $y$ direction of $3 \mathrm{~mm}(0.6 \mathrm{~m}$ full scale) from the centre to the edge of the turntable. 
3. Spatial accuracy of the LDA associated with the measurement volume. Seeding particles can go through the volume over a vertical depth of about $0.3 \mathrm{~m}$ full scale. Hence, velocity statistics are also space-averages, which is important in regions with very large flow gradients.

Great care was taken to minimize these uncertainties where possible. The comparatively large scale of the model has the benefit that spatial inaccuracies are proportionally small in full scale.

\subsection{Approach-Flow Boundary Layer}

In the flow-development section upwind of the model a fully rough boundary-layer flow (labelled BL-0) was physically modelled (Appendix 2, overview of parameters in Table 5). After passing through the flow straightener at the tunnel inlet, the boundary layer was initiated by a set of five Irwin spires (Fig. 1c, d). The flow developed further by passing over a sparse (240 mm spacing in $x, y$; i.e. $48 \mathrm{~m}$ in full scale) staggered array of floor roughness elements comprised of sharp, thin metal plates (length: $80 \mathrm{~mm}$, height: $20 \mathrm{~mm}$; i.e. $16 \mathrm{~m}$ and $4 \mathrm{~m}$ in full scale).

The horizontal homogeneity of the approach flow was tested at a distance of $12 \mathrm{~m}$ from the tunnel inlet. Lateral transects $(y= \pm 600 \mathrm{~mm}$, i.e. $\pm 120 \mathrm{~m}$ full-scale, from the tunnel centre) show that horizontal variations of mean flow and turbulence statistics ( $U-W$ mode; full-scale heights of $81 \mathrm{~m}$ and $134.3 \mathrm{~m}$ ) are smaller than the corresponding statistical standard errors (Sect. 3.2).

The flow in the BL-0 case is typical of low-rise urban areas and less rough than would be expected in the densely built-up and often high-rise parts of central London close to the model domain. From the analysis of the extent of the logarithmic region of the vertical profile of $U$ (Fig. 13a), the extent of the modelled ISL was estimated as $9 \mathrm{~m} \leq z \leq 60 \mathrm{~m}$ in full scale, corresponding to about $3.8 H_{\text {NoTall }}\left(H_{\text {NoTall }}=13.4 \mathrm{~m}\right.$ : mean $H_{\text {ave }}$ of the No Tall ${ }_{\mathrm{N}, \mathrm{SE}}$ cases; Table 3). A friction velocity $\left(u_{*}\right)$ of $0.11 \mathrm{~m} \mathrm{~s}^{-1}$ (i.e. $0.056 U_{r e f}$ ) is derived from averaging the vertical turbulent momentum flux, $-\overline{u^{\prime} w^{\prime}}$, over the ISL extent determined from the $U(z)$ profile. Aerodynamic roughness parameters, $z_{0}=0.16 \mathrm{~m}$ and $z_{d}=3.4 \mathrm{~m}$, were derived from a fit to the logarithmic wind profile in the ISL, $U(z)=\left(u_{*} / \kappa\right) \ln \left(\left(z-z_{d}\right) / z_{0}\right)$, where $\kappa=0.4$ is the von Kármán constant. At $z=134.3 \mathrm{~m}, U \approx U_{\text {ref }}$ so that this height specifies the depth of the modelled boundary layer $\left(\delta_{B L-0}\right)$. Hence, the boundary layer of the approach flow is relatively shallow compared to the tall buildings in the model domain $\left(\delta_{B L-0} / H_{81}=1.7\right.$ and $\left.\delta_{B L-0} / H_{134}=1\right)$. For the No Tall configuration the ratio increases to $\delta_{B L-0} / H_{\text {NoTall }}=10$.

\section{Results}

\subsection{Low Height Variability}

The No Tall cases are considered as a reference state of RSL and ISL flow characteristics. Median vertical flow profiles of all No Tall ${ }_{N, S E}$ sites (Fig. 2b, e) are shown in Fig. 3 together with the BL-0 approach-flow conditions. For both model orientations, the variability in building heights for the No Tall cases is approximately $6 \mathrm{~m}$ (Table 3 ), with $H_{\text {NoTall }}=13.4 \mathrm{~m}$. Minor differences in morphometric parameters are due to buildings being removed between the two model orientations. 
(a)

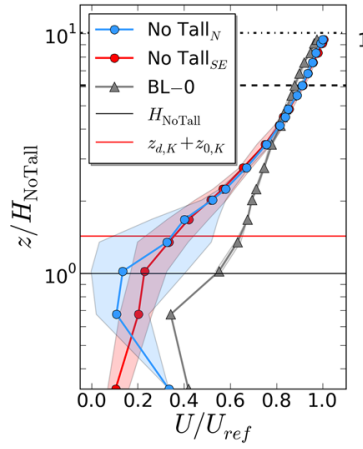

(b)

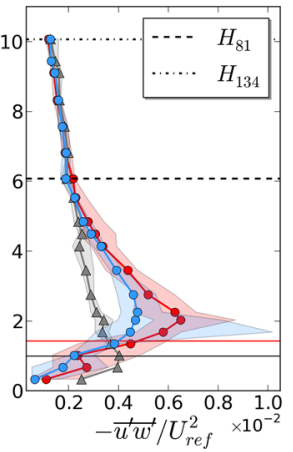

(c)

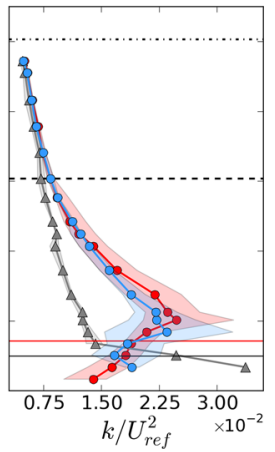

(d)

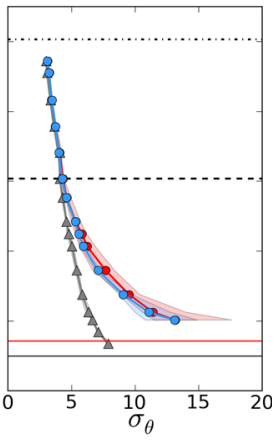

Fig. 3 Vertical profiles in the No Tall ${ }_{\mathrm{N}, \mathrm{SE}}$ cases and the horizontally homogeneous approach flow (BL-0) of a mean longitudinal velocity component $\left(U ; y\right.$-axis logarithmic), b vertical turbulent momentum flux $\left(-\overline{u^{\prime} w^{\prime}}\right)$, c turbulence kinetic energy $(k)$, and $\mathbf{d}$ standard deviation of the horizontal wind direction $\left(\sigma_{\theta}\right)$. The No Tall case profiles are medians of all sites (Fig. 2b, e), with interquartile range (shading)

The profiles of the longitudinal velocity component ( $U$; Fig. 3a) show logarithmic behaviour and relatively small spatial variations (narrow interquartile range) above a height of $3 H_{\text {NoTall }}(40.2 \mathrm{~m})$, which can be considered the upper limit of the RSL (i.e. the blending height) without tall buildings included. Expectedly, values of $U$ in the RSL and UCL show large site-to-site variability. The logarithmic part of the upwind boundary layer (BL-0) occurs closer to the surface between 1 and $4.5 H_{\text {NoTall }}$ (Sect. 3.3).

There is a distinct increase in turbulence levels in response to the roughness change between the flow-development section and the model. For the No Tall cases, the vertical turbulent momentum flux $\left(-\overline{u^{\prime} w^{\prime}}\right.$; Fig. 3b) and turbulence kinetic energy (TKE, $k=\frac{1}{2} \overline{\left(u^{\prime 2}\right.}+$ $\left.\overline{v^{\prime 2}}+\overline{w^{\prime 2}}\right)$; Fig. 3c) peak around a height of $2 H_{\text {NoTall }}(26.8 \mathrm{~m}$ full scale). Differences between the median No Tall profiles are linked to different local effects on individual profiles and different sample sizes. Profiles of the standard deviation of the horizontal wind direction $\left(\sigma_{\theta}\right.$; Fig. 3d) are shown above the level of maximum $-\overline{u^{\prime} w^{\prime}}$. Below that, in the lower parts of the RSL and within the urban canopy, the horizontal flow may not have a single 'preferred' direction. The turbulence characteristics (Fig. 3b-d) converge back to the BL-0 state at around 6 to $7 H_{\text {NoTall }}$. Note that the tall building rooftops are located at heights of around $6 H_{\text {NoTall }}$ (building $\mathrm{T}_{81}$ ) and $10 H_{\text {NoTall }}$ (building $\mathrm{T}_{134}$ ).

\subsection{Wake-Roughness Interaction}

The momentum deficit in the wake of a building is traditionally assessed by the velocity difference $(\Delta U)$ to the upwind (or ambient) flow. We use velocity differences to study effects of, (i) tall buildings in an urban canopy (Core-No Tall cases), (ii) tall buildings in isolation (Tall-BL-0), (iii) an urban canopy surrounding tall buildings (Core-Tall), and (iv) increased building heights in the near-wake of a tall building (Increased-Tall).

Figures 4 and 5 show vertical profiles of $U$ and differences $\Delta U$ between model configurations for sites on longitudinal transects through buildings $\mathrm{T}_{81}$ and $\mathrm{T}_{134}$ (site codes as in Fig. 2c, f). Results from the ADMS-Build wake model (Appendix 1) are shown for the Tall and Core configurations (Figs. $4 \mathrm{a}, \mathrm{b}$ and $5 \mathrm{a}$, b) at sites in the main wake (discussion in Sect. 4.2.2). 
(a)

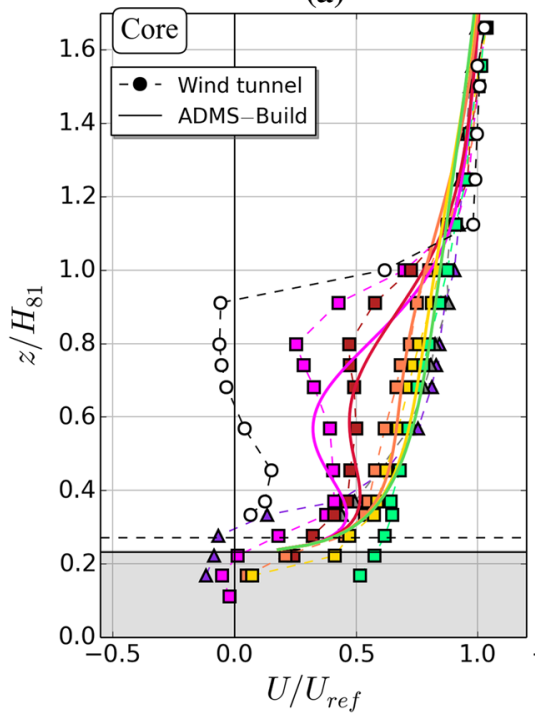

(c)

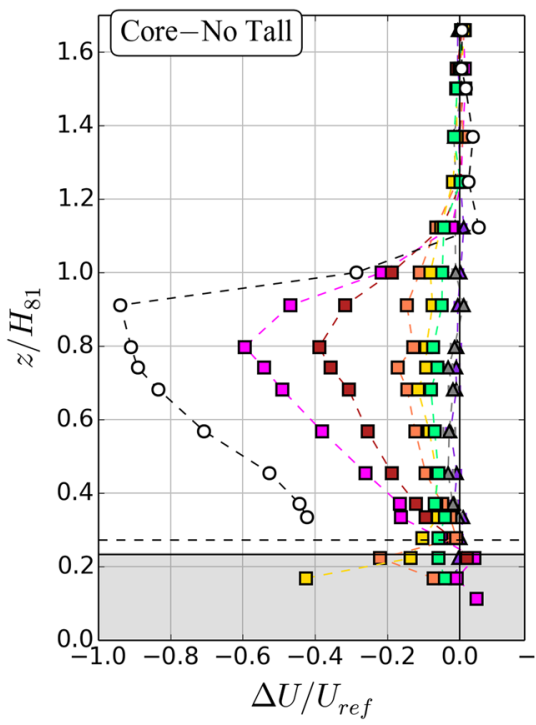

(b)

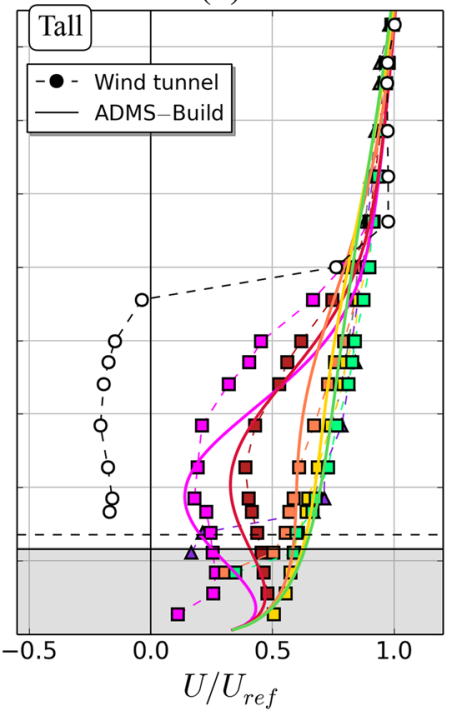

(d)

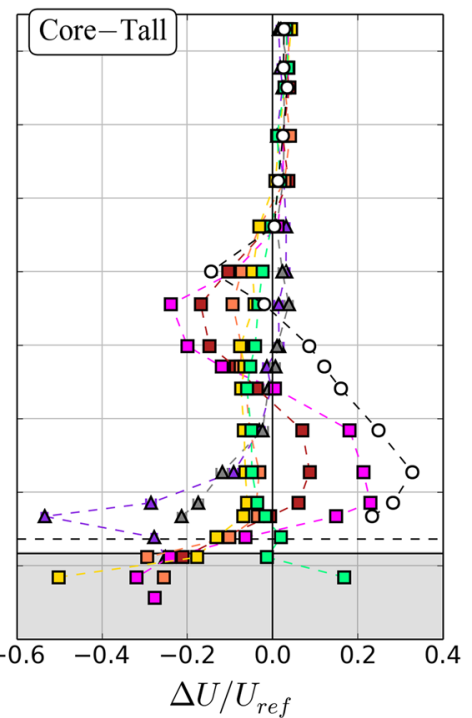

\begin{tabular}{|c|c|c|c|c|}
\hline$-\Delta-N 1$ & юО- N3 & $+\square-N 5$ & - N7 & - No Tall $z_{0, K}+z_{d, K}$ \\
\hline$-\Delta-N 2$ & $-\square-N 4$ & $-\square-N 6$ & $-\square-N 8$ & - - - Core $_{N} z_{0, K}+z_{d, K}$ \\
\hline
\end{tabular}

Fig. 4 Vertical profiles of $U$ for sites on a longitudinal transect through building $\mathrm{T}_{81}$ (north orientation) for the, a Core, and $\mathbf{b}$ Tall cases; and profiles of the velocity difference $\Delta U$ (note different $x$-axis scales) for $\mathbf{c}$ Core-No Tall, and $\mathbf{d}$ Core-Tall (site codes in Fig. 2c). Wind-tunnel data shown as symbols. Triangle: site upwind of the tall building, circle: near-wake site, square: main-wake site. ADMS-Build model results (thick solid lines) in the main wake shown in (a, b). Shading indicates $H_{a v e}+\sigma_{H}$ for No Tall ${ }_{\mathrm{N}}$ (Table 3) 
(a)

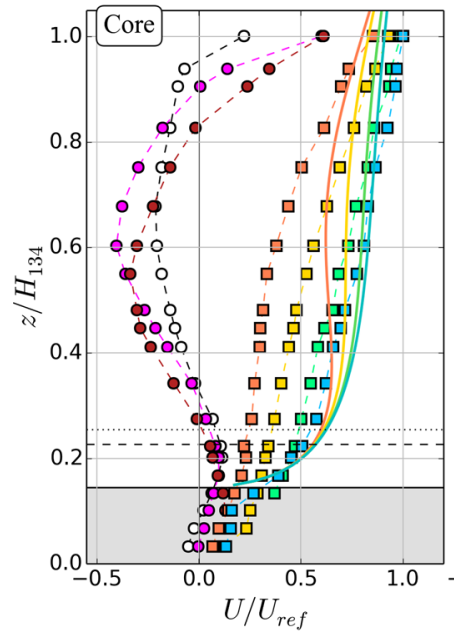

(d)

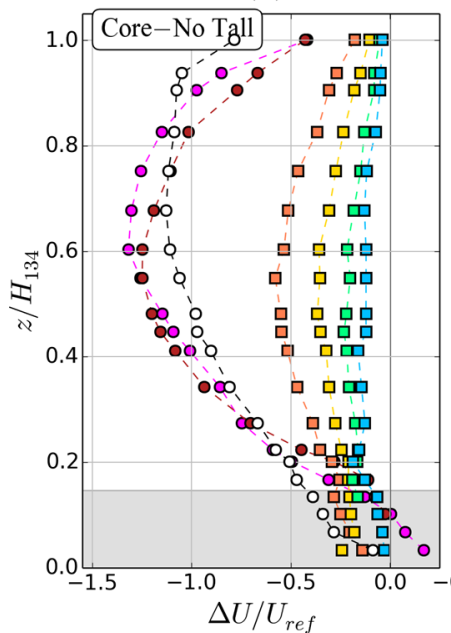

(b)

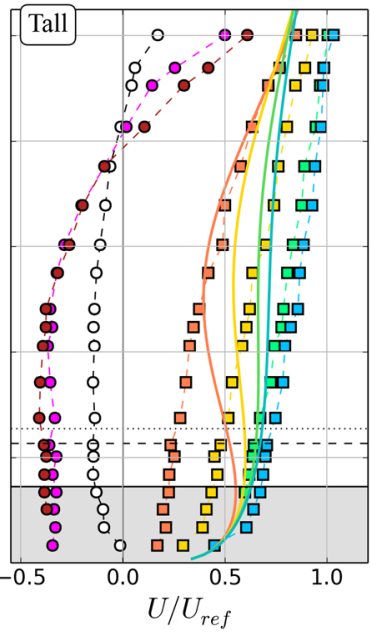

(e)

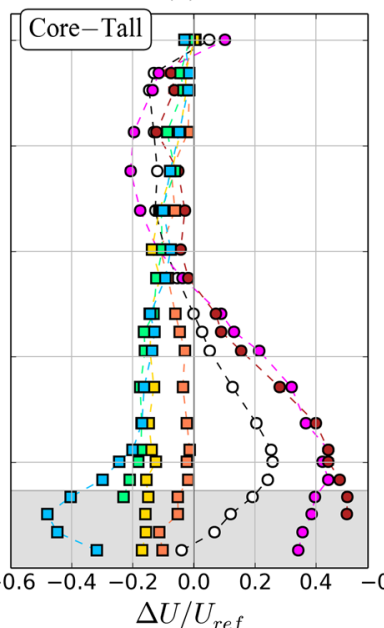

(c)

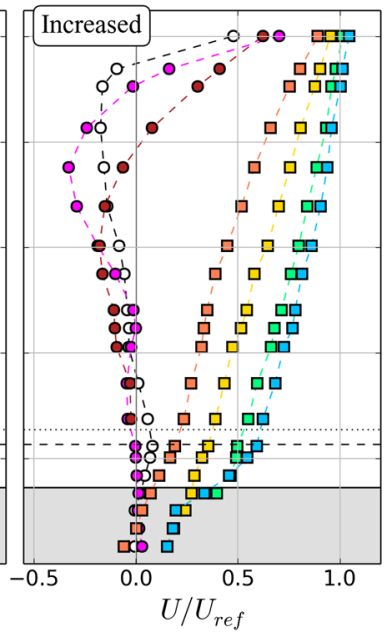

(f)

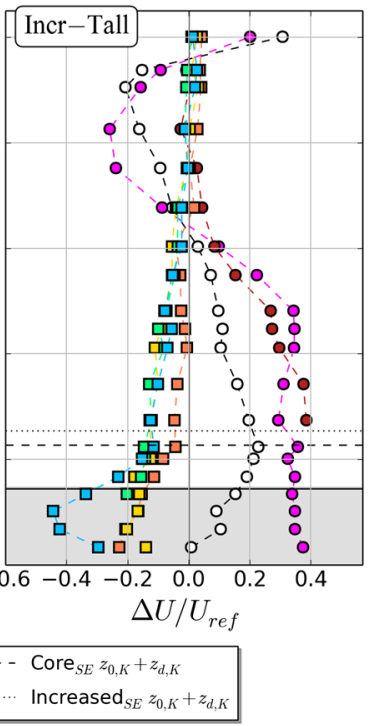

Fig. 5 As Fig. 4, but for sites on a longitudinal transect through building $\mathrm{T}_{134}$ (south-east orientation) plus (c, f) the Increased case ( shown for the a Core, and b Tall cases. Shading indicates $H_{a v e}+\sigma_{H}$ for No Tall SE (Table 3)

\subsubsection{Flow in the Near-Wake}

In all geometries including the tall buildings, sites N3 ( $\mathrm{T}_{81}$ building, Fig. 4a, b) and $\mathrm{S} 1-\mathrm{S} 3$ ( $\mathrm{T}_{134}$ building, Fig. $5 \mathrm{a}-\mathrm{c}$ ) are located in the near-wake region that is characterized by flow reversal $(U<0)$ over at least parts of the velocity profile in the cavity region on the leeward side of the tall buildings. The along-wind extent of the near-wake (or cavity zone) observed in the wind tunnel, $L_{R}^{\mathrm{WT}}$ (Table 4), for building $\mathrm{T}_{81}$ is within the range $0.1 H_{81}<L_{R}^{\mathrm{WT}}<0.6 H_{81}$ 
Table 4 Effective building heights ( $\left.H_{\text {eff }}\right)$ and cavity lengths based on the ADMS-Build model approach $\left(L_{R}\right.$; Eq. 2) and wind-tunnel measurements $\left(L_{R}^{W T}\right)$ for the Tall and Core configurations

\begin{tabular}{llll}
\hline & & $\mathrm{T}_{81}$ (north) & $\mathrm{T}_{134}$ (south-east) \\
\hline Tall & $L_{R}^{W T}$ & $0.1<L_{R}^{W T} / H_{81}<0.6$ & $0.9<L_{R}^{W T} / H_{134}<1.9$ \\
& $L_{R}$ & $0.68 H_{81}$ & $1.22 H_{134}$ \\
Core & $H_{\text {eff }}(\mathrm{m})$ & 62.7 & 115.2 \\
& $L_{R}^{W T}$ & $0.13<L_{R}^{W T} / H_{81, \text { eff }}<0.78$ & $1.1<L_{R}^{W T} / H_{134, \text { eff }}<2.2$ \\
& $L_{R}$ & $0.82 H_{81, \text { eff }}$ & $1.4 H_{134, \text { eff }}$ \\
\hline
\end{tabular}

(i.e. between sites N3 and N4; Fig. 2c) and $0.9 H_{134}<L_{R}^{\mathrm{WT}}<1.9 H_{134}$ (i.e. between S3 and S4; Fig. 2f) for building $\mathrm{T}_{134}$. Note that $L_{R}^{\mathrm{WT}}$ is measured from the downwind building face, not the centre.

In the ADMS-Build wake model the cavity length $L_{R}$ is derived from the building geometry (Eq. 2 with $L=L_{f}$, Table 1). When surrounded by the low-rise canopy we define the effective (reduced) height of the tall buildings in the Core cases as $H_{\mathrm{eff}}=H-\left(z_{0, K}+z_{d, K}\right)$ to account for the vertical displacement of the flow profiles above the canopy and the roughness variability of the surroundings. This is consistent with the definition of the inflow profiles for the ADMS-Build model for the Core configurations (Appendix 1). Using the roughness length and displacement height of the No Tall cases (Table 3) this results in $H_{81 \text {, eff }}=62.7 \mathrm{~m}$ $\left(\mathrm{T}_{81} ;\right.$ Core $\left._{\mathrm{N}}\right)$ and $H_{134, \text { eff }}=115.2 \mathrm{~m}\left(\mathrm{~T}_{134}\right.$; Core $\left.\mathrm{SE}\right)$. The calculated $L_{R}$ values fall within the ranges determined in the experiment for building $\mathrm{T}_{134}$, and are only slightly larger for $\mathrm{T}_{81}$ (Table 4). As $L_{R} / H \propto W_{c} / H$, the reduced near-wake extent for the $\mathrm{T}_{81}$ tower is related to the smaller building aspect ratio $\left(W_{c} / H\right)$ compared to $\mathrm{T}_{134}$.

In the near-wake region of the isolated buildings (Tall configuration), $U$ is almost uniform with height over large portions of the wake before increasing monotonically: for building $\mathrm{T}_{81}$ up to $z / H_{81} \approx 0.8$ (site N3; Fig. 4b); for $\mathrm{T}_{134}$ up to $z / H_{134} \approx 0.8$ (site $\mathrm{S} 1$ ) and 0.5 (sites $\mathrm{S} 2 / \mathrm{S} 3$; Fig. 5b). When surrounded by the low-rise canopy the tall-building wakes show a reduction in the strength of flow reversal in the recirculation region above $z_{0, K}+z_{d, K}$ (Figs. 4a, 5a). For building $\mathrm{T}_{134}$ this occurs up to $0.5 \mathrm{H}_{134}$ in the Core case (Fig. 5e) and $0.6 H_{134}$ for the Increased geometry (Fig. 5f). In the lee of the $\mathrm{T}_{81}$ tower, flow reversal at site $\mathrm{N} 3$ is reduced over nearly the entire building height (Fig. 4d) with $U>0$ between 0.3 and $0.6 H_{81}$ (Fig. 4a). The structure of the cavity zone is noticeably altered from the Tall to Core to Increased configurations in response to the presence of the urban canopy and interaction with RSL turbulence. Similar changes of the near-wake structure, notably a reduction in the cavity length with increasing turbulence intensity of the ambient flow, occur for isolated buildings (Ogawa et al. 1983).

The low-rise buildings modify the shape of the Core-case $U$ profiles in two ways compared to the Tall cases: (i) the sheltering effect of the urban canopy reduces the magnitude of the longitudinal velocity below $z_{0, K}+z_{d, K}$ (No Tall case), and (ii) larger vertical mean-flow gradients, $\partial_{z} U$, occur throughout the wake and at roof-level of the towers (Figs. 4a, 5a, c). The low-level buildings reduce the effective vertical depth, $z_{R}$, over which flow reversal occurs in the lee of the tall building above the canopy as the centre of the recirculation zone is displaced upwards. At site S2 $\left(d_{x} / H_{134}=0.55\right)$, for example, distinct peaks in the magnitude of backflow are evident at heights of $z / H_{134} \approx 0.6$ (Core case) and $z / H_{134} \approx 0.75$ (Increased case), at which flow speeds in the Tall case already start to increase. In the Tall set-up, the vertical extent of the flow recirculation region, $z_{R} / H_{134}$, is approximately 0.82 , 
0.8 and 0.76 at sites S1, S2 and S3 (Fig. 5b), respectively. For the Core geometry the extent reduces to $0.63,0.59,0.56$ (Fig. 5a) and for the Increased case to $0.62,0.45,0.5$ (Fig. 5c) at the same locations.

For building $\mathrm{T}_{81}$, the large $\partial_{z} U$ at rooftop for both the Tall and Core set-ups (site N3; Fig. 4a, b) suggests shear-layer separation at the trailing edge of the roof, i.e. re-attachment to the roof occurred after the initial separation at the leading edge. This is accompanied by a small momentum excess above roof-level $\left(\approx 0.05 U_{\text {ref }}\right.$ at $z / H_{81}=1.1$, Fig. $\left.4 \mathrm{c}\right)$. This is in agreement with near-wake specifications in the ADMS-Build model, in which re-attachment is assumed to occur if $L \geq \min \left(H, 0.5 W_{c}\right)$. However, re-attachment is not only controlled by the building's geometry, but also by the nature of the ambient flow and the turbulence structure at roof-level (Fackrell 1984). Based on pressure measurements on the roof of an isolated cubic building (Castro and Robins 1977), permanent re-attachment occurs if the ratio of upwind boundary-layer depth to building height is $>1.4\left(\right.$ Tall $_{\mathrm{N}}: \delta_{B L-0} / H_{81}=1.7$, Sect. 3.3) and intermittent or absent re-attachment if it is $<1.4\left(\right.$ Tall $_{\mathrm{SE}}: \delta_{B L-0} / H_{134}=1$ ). Furthermore, higher turbulence intensity in the ambient flow promotes re-attachment to the top and sides of the building (Castro and Robins 1977).

The orientation of the triangular tower $\mathrm{T}_{134}$ to the south-easterly approach flow creates a set of strong roof vortices for which re-attachment can be expected (Hunt 1971; Hunt et al. 1978). Although no measurements are available above roof-level to confirm this, the flow structure in the Tall case closest to the building (S1) suggests that re-attachment may be intermittent as the velocity deficit is still large at $z / H_{134}=1$ (Fig. 5b). In the Core and Increased configurations, however, $\partial_{z} U$ near roof-level is larger (Fig. 5a, c), which implies a more stable re-attachment of the shear layer.

\subsubsection{Flow in the Main Wake}

In the main-wake region, flow reversal ceases and the wake is characterized by a momentum deficit. The impact of the tall building on the ambient flow decays with longitudinal distance $\left(d_{x} / H\right.$; Fig. 6). The velocity deficit $(\Delta U)$ for the Tall configurations (Fig. 6a, c) is assessed by the Tall-BL- 0 difference $(U(z)$ for BL-0 as in Fig. 13a) and for the Core and Increased cases as the difference to the No Tall reference state (Fig. 6b, d, e). Assuming the velocity difference decays as $\left(d_{x} / H\right)^{-p}$ (e.g. Hosker 1983), the fits in Fig. 6 indicate different flowrecovery behaviours in the different configurations (fit parameters for all curves are given in the Online Resource, Table ESM_1). For the Tall cases (Fig. 6a, c), for which the decay rates are quite homogeneous with height, $p \approx 1.5$ on average for building $\mathrm{T}_{81}$ and $\approx 2.0$ for $\mathrm{T}_{134}$. Hence $\Delta U$ in the wake of the higher and wider $\mathrm{T}_{134}$ building decays more rapidly with downwind distance, which could result from the stronger lateral fanning of the wake compared to the slender hexagonal $\mathrm{T}_{81}$.

The specifications in the ADMS-Build model define the decay of the velocity deficit $\Delta U$ with downwind distance at the building centreline $(y=0)$ as

$$
\Delta U \propto \ell_{y}^{-1} \ell_{z}^{-3} z \exp \left(-z^{2} \ell_{z}^{-2}\right)
$$

following Eq. 3 in Appendix 1, where $\xi=z / \ell_{z}$, and the length scales $\ell_{y, z} \propto x^{1 / 2}$ (Eq. 6, setting $\left.x_{0}=0\right)$. Hence, $\Delta U \propto x^{-2} \exp \left(-z^{2} x^{-1}\right)$. For small $z^{2} x^{-1}, \Delta U \propto x^{-2}$ after which the decay rate along $x$ decreases considerably with increasing height unlike in the experiment (Tall cases).

For both buildings, the wake structure and decay rates vary more strongly with height if the tall building is embedded in an urban canopy (Fig. 6b, d, e). For the Core cases, in the 
(a) $\mathrm{T}_{81}$

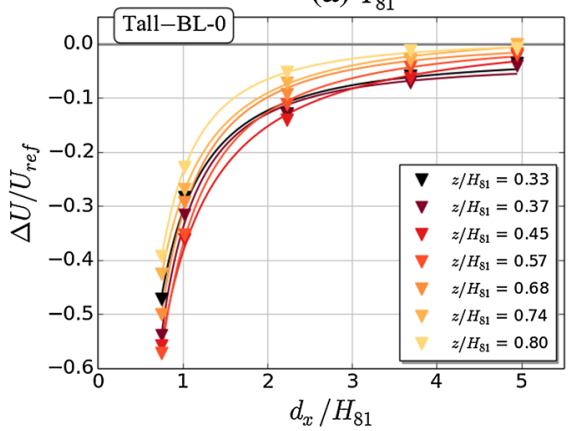

(c) $\mathrm{T}_{134}$

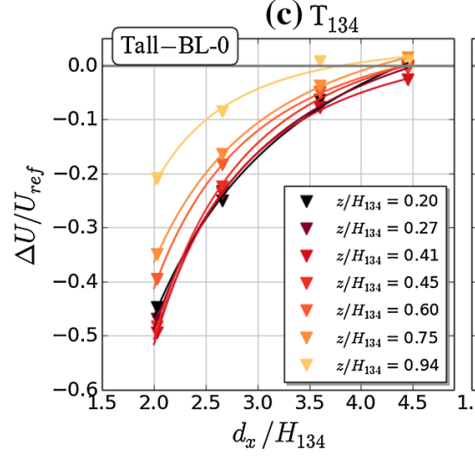

(b) $\mathrm{T}_{81}$

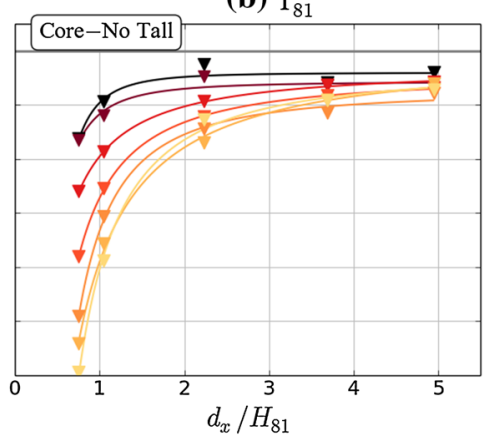

(d) $\mathrm{T}_{134}$

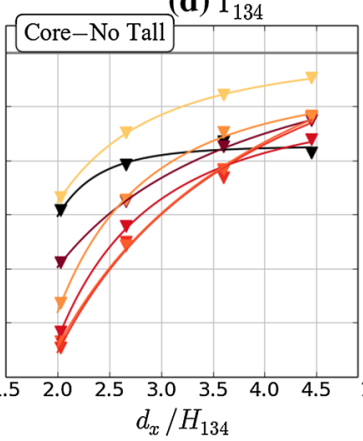

(e) $\mathrm{T}_{134}$

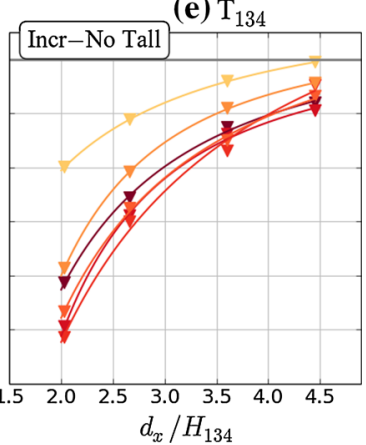

Fig. 6 Velocity deficit $\Delta U$ with $d_{x} / H$ for different heights in the main wake of (a, b) building $\mathrm{T}_{81}$ (sites N4-N8, Fig. 2c); (c-e) building $\mathrm{T}_{134}$ (sites S4-S7, Fig. 2f). $\Delta U$ is obtained from the difference between (a, c) Tall-BL-0, (b, d) Core-No Tall, and (e) Increased-No Tall. Solid lines show fits of the form $f(x)=a+b x^{-p}$

peak region of TKE and vertical turbulent momentum transport of the No Tall case RSL (Fig. 3b, c) the wake decay is rapid initially, but further downwind $\Delta U$ varies little with $d_{x}$ (building $\mathrm{T}_{81}$ at $z / H_{81}=0.33$, Fig. $6 \mathrm{~b} ; \mathrm{T}_{134}$ at $z / H_{134}=0.20$, Fig. $6 \mathrm{~d}$ ).

Compared to the Tall-case profiles, for building $\mathrm{T}_{134}$ velocities are further reduced in the main wake in the Core configuration at all heights, even well above the RSL (Core-Tall $<0$; Fig. 5e). For building $\mathrm{T}_{81}$, however, the nature of the Core-Tall difference is more complex at sites N4 and N5 that are closest to the near-wake (Fig. 4d): the Core-case wake is weaker compared to Tall below $z / H_{81} \approx 0.7$ and noticeably enhanced above, reflecting the differences in the height $z_{\max }$ associated with $\min (U)$ above the RSL (Fig. 4a, b). Although no flow reversal occurred at sites N4/N5, qualitatively this behaviour is very similar to that observed at the near-wake sites S1-S3 behind building $\mathrm{T}_{134}$ (Fig. 5e). Further downwind of building $\mathrm{T}_{81}$ (sites N6-N8), the wake in the Core set-up is amplified at all levels above the canopy, as found for building $\mathrm{T}_{134}$ at similar distances.

Interestingly, increasing the height of the canopy in the near-wake region of building $\mathrm{T}_{134}$ reduces the velocity deficit in the main wake. The Increased-Tall differences are small between $0.5 H_{134}<z \leq 1$ (Fig. 5f) and the difference between the Core and Increased cases is negative throughout the main wake above $z_{0, K}+z_{d, K}$ (see profiles in Fig. 5a, c). This is also apparent in the along-wind decay of $\Delta U$ (Fig. 6e), particularly close to roof-level, where $\Delta U \approx 0$ at $z / H_{134}=0.94\left(d_{x} / H_{134}=4.45\right)$ as in the Tall case (Fig. 6c). This behaviour may be related to strong damping of flow reversal over larger parts of the near-wake compared 
to the Core set-up (sites S1-S3; Fig. 5c), which results in reduced initial velocity defects at the start of the main wake (Fig. 6d, e). In addition to that, sites S4-S7 are affected by secondary wake effects downwind of the increased buildings, leading to enhanced turbulent mixing that can contribute to a reduced velocity deficit, in agreement with theoretical and empirical considerations (Castro and Robins 1977). Furthermore, since tower $\mathrm{T}_{134}$ is located at the model edge, the displacement of the BL-0 approach flow locally leads to an increase in the vertical flow component. This is expected to be further enhanced in the Increased configuration and results may be different if building $\mathrm{T}_{134}$ were embedded further downwind in the model.

The ADMS-Build wake model shows remarkably good agreement with the measured Tallcase profiles for building $\mathrm{T}_{81}$ throughout the main wake (Fig. 4b). However, the observed upward shift in $z_{\max }$ for the Core case at sites N4/N5 is not represented (Fig. 4a). While accounting for the reduction of the effective building height in the Core case improves the results for building $\mathrm{T}_{81}$, this measure is not sufficient to represent the structural changes of the wake if the tower is embedded in an urban canopy. Overall larger differences between model and experiment are evident in the wake of the triangular building $\mathrm{T}_{134}$, even when considered in isolation, as the enhanced wake decay rate is not captured. Using $H_{\text {eff }}$ for the Core-configuration modelling in this case did not result in an improved representation of the wake. Since the model was neither designed to represent the impact of an urban canopy surrounding the tall building nor the flow response to non-cuboid building shapes, the results are not surprising, but help to identify model development needs.

\subsubsection{Vertical Mean Flow Characteristics}

Figure 7 shows profiles of $W / U_{h}$, where $U_{h}=\sqrt{U^{2}+V^{2}}$ is the horizontal wind speed, together with the flow angle in the vertical plane, $\theta_{z}=\arctan \left(W / U_{h}\right)$, for the three sites closest to the tall buildings.

Qualitative and quantitative changes in the patterns of updrafts and downdrafts for the different test geometries are evident. For building $\mathrm{T}_{81}$ there is a large amplification of the characteristic updrafts on the leeward building side at site $\mathrm{N} 3$ in the Core case $\left(\max \left(W / U_{h}\right) \approx 10\right.$; Fig. 7a). The much stronger upward flow deflection $\left(50^{\circ}<\theta_{z}<90^{\circ}\right.$ for $\left.0.3<z / H_{81}<1\right)$ is linked to the initial confinement of the horizontal flow in the street canyon between building $\mathrm{T}_{81}$ and the downwind 24-m tall neighbouring building (Fig. 2a). Once the updraft clears the height of the downstream neighbour most of the air initially escapes in the longitudinal direction. This is consistent with the local increase of $U$ to positive values above the low-level canopy at site N3 (Fig. 4a) and S1 (Fig. 5a, c), before backflow in the displaced recirculation zone of the tall building becomes dominant. Drastic effects of the underlying buildings are also evident at main-wake sites N4 and N5 (Fig. 7b, c). While for the Core geometry $W$ remains positive between $0.4 \leq z / H_{81} \leq 0.8$ and negative at the top of the low-level canopy, the Tall-case profiles have upward then downward flow.

For building $\mathrm{T}_{134}$, qualitative differences mainly occur at $\mathrm{S} 1$, closest to the building $\left(d_{x} / H_{134}=0.27\right.$; Fig. $\left.7 \mathrm{~d}\right)$. While the Tall case has strong upward flow at all levels, this is only the case above $z / H_{134} \approx 0.6$ for the Core and Increased cases.

\subsubsection{Wake Turbulence}

Figure 8 shows profiles of TKE $(k)$, vertical turbulent momentum transport $\left(-\overline{u^{\prime} w^{\prime}}\right)$ and integral turbulence time scale $\left(\tau_{u}\right)$ of the $u$-component for building $\mathrm{T}_{81}$ (Tall and Core cases) 

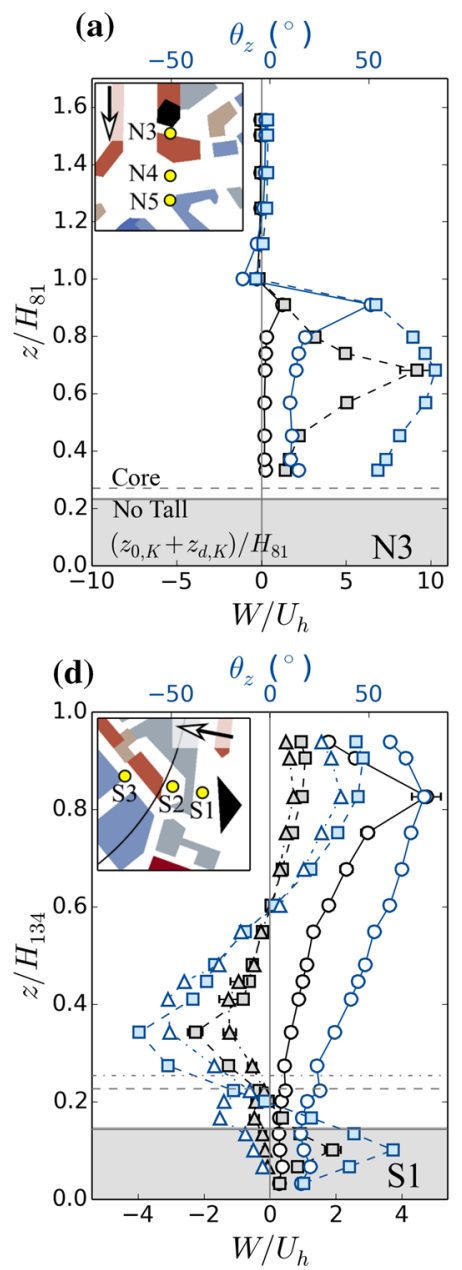

(b)

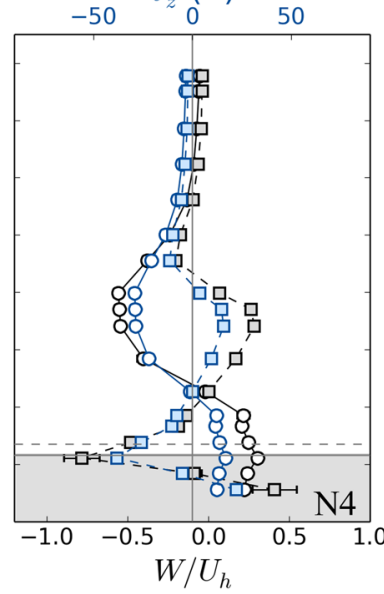

(e)

(c)
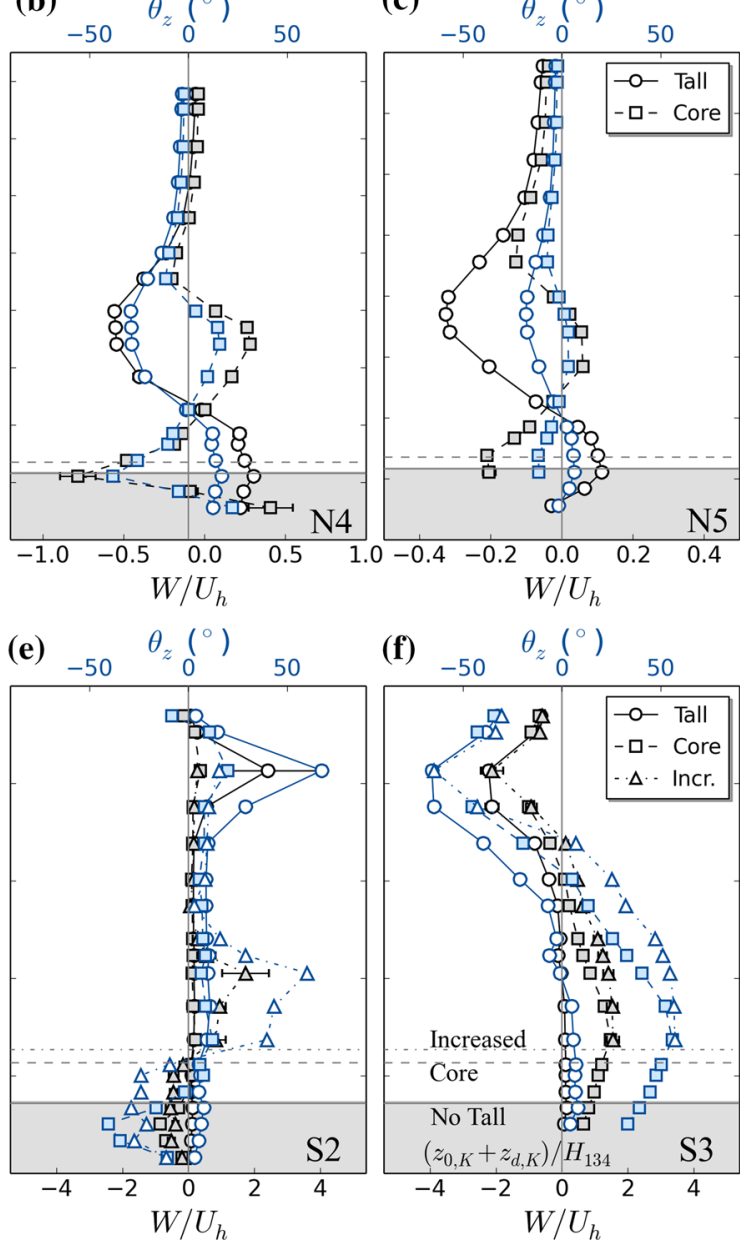

Fig. 7 Mean vertical velocities $W$ (normalized by horizontal wind speed $U_{h}$ ) and the flow angle in the vertical plane $\left(\theta_{z} \in\left[-90^{\circ},+90^{\circ}\right]\right.$; top axis, blue symbols), at sites closest to a-c building $\mathrm{T}_{81}$ (north orientation), and $\mathbf{d}-\mathbf{f}$ building $\mathrm{T}_{134}$ (south-east)

for the same sites as in Fig. 4. $\tau_{u}$ is determined by integrating over the $1 \mathrm{D}$ temporal autocorrelation of $u^{\prime}$ down to a cut-off point of 0.25 . An empirically determined correction factor of 1.336 is then applied to compensate for not integrating down to zero.

Turbulence characteristics are qualitatively similar for building $\mathrm{T}_{134}$ (Online Resource: Figs. ESM_2, ESM_3). Compared to the N1/N2 locations upwind of building $\mathrm{T}_{81}$, at the downwind sites $k$ is enhanced by up to a factor of 10 (e.g. site N4 in the Tall case at $z / H_{81}=$ 0.7). In both geometries, at site $\mathrm{N} 3$ the peak of $k$ at $z / H_{81}=1$ is caused by strong contributions of $\overline{u^{\prime 2}}$ in the shear layer $\overline{u^{\prime 2}}: \overline{v^{\prime 2}}: \overline{w^{\prime 2}}$ as $1: 0.5: 0.5$ at $z / H_{81}=1$; Online Resource: Fig. ESM_4). While above building $\mathrm{T}_{81}$ 's roof $k$ in the Tall case rapidly converges back to the upwind flow conditions at any longitudinal distance in the wake, in the Core geometry it remains enhanced slightly longer. The larger peak of $k$ closest to the building and the larger amount of shear developed in the Core case could indicate structural differences of 

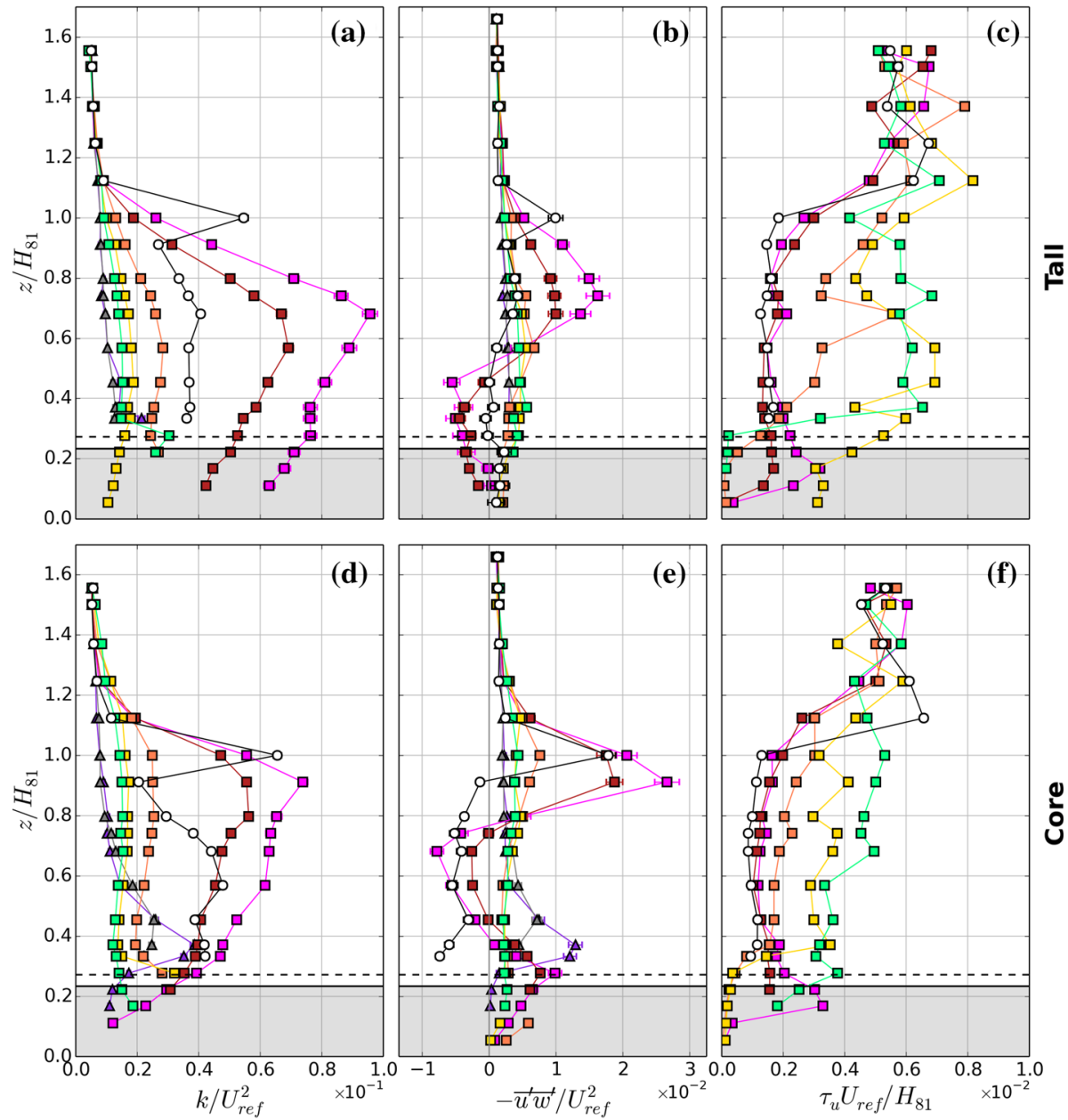

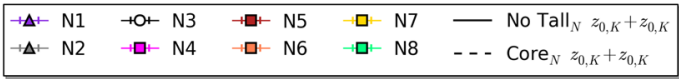

Fig. 8 Vertical profiles of $\mathbf{a}, \mathbf{d}$ turbulence kinetic energy, $\mathbf{b}$, e vertical turbulent momentum flux, and $\mathbf{c}, \mathbf{f}$ turbulence integral time scales of the $u$-component on a longitudinal transect through building $\mathrm{T}_{81}$ (north orientation) in the a-c Tall and d-f Core set-ups. Symbols as in Fig. 4

the roof vortex compared to the Tall set-up and reflects the fact that the region of maximum velocity deficit in the Core geometry lies closer to the roof of the tower. Likewise, the different heights of $\max (k)$ in the main wake (sites N4-N8, Tall case: $z / H_{81} \approx 0.7$; Core case: 0.9$)$ can be attributed to the displacement of the Core-case profiles above the canopy $\left(\left(z_{0, K}+z_{d, K}\right) / H_{81} \approx 0.25\right)$. Greater TKE values at sites N4/N5 (upwind part of the mainwake) for the Tall case throughout the vertical extent of the wake are associated with large variances of the lateral velocity component $\left(\overline{v^{\prime 2}}\right)$, with $\max \left(\overline{v^{\prime 2}}\right)$ being larger by a factor of $\approx 1.5$ at both sites compared to the Core geometry (Online Resource: Fig. ESM_4).

In both configurations, $-\overline{u^{\prime} w^{\prime}}$ changes sign in response to the sign change of $\partial_{z} U$ between $0.4<z / H_{81}<1$ (sites N1-N3; Fig. 4a, b). In the Core set-up at sites N4/N5 there are notable 
peaks of $-\overline{u^{\prime} w^{\prime}}>0$ (downward momentum transfer) at the top of the low-level canopy (Fig. 8e), while in the Tall configuration in that region the transfer is oriented upwards $\left(-\overline{u^{\prime} w^{\prime}}<0\right.$; Fig. 8b). Momentum exchange in the Core configuration is also enhanced at the roof-level of building $\mathrm{T}_{81}$, where fluxes at sites N3-N5 exceed the Tall-case values by factors of 1.5-2. At roof-level of building $\mathrm{T}_{134}$, fluxes are enhanced even more strongly at site $\mathrm{S} 1$ by factors of 2.5 for the Core case and 3 for Increased (Online Resource: Fig. ESM_3). The large momentum exchange at roof-level compared to the isolated building case is associated with larger $\partial_{z} U, \overline{u^{\prime 2}}$ and $\overline{w^{\prime 2}}$, contributing to the reduction of the recirculation intensity. This has also been observed for isolated buildings in highly turbulent boundary layers (e.g. Becker et al. 2002).

Upwind of building $\mathrm{T}_{81}, k$ and $-\overline{u^{\prime} w^{\prime}}$ (sites N1/N2; Fig. 8d, e) are locally enhanced in the Core case due to the presence of some taller buildings with heights between 24 and $28 \mathrm{~m}$ (Fig. 2a), while downwind of location N3 the surrounding structures are notably lower $(H<12 \mathrm{~m})$. Changes of wake turbulence in the Core geometry are accompanied by a reduction of $\tau_{u}$ below $z / H_{81}=0.9$ in the main wake (Fig. $8 \mathrm{c}, \mathrm{f}$ ), reflecting the reduction of length scales of the energy-containing eddies generated in the RSL and UCL compared to the conditions in BL-0 approaching the isolated tall building.

\subsubsection{Instantaneous Flow Structure}

To understand better the observed response of mean flow and turbulence to changes in geometry, the flow structure is evaluated in terms of frequency distributions of the instantaneous vertical velocity component $(w)$ and horizontal wind direction $(\theta=$ $\arctan (v / u))$.

In the Tall case for building $\mathrm{T}_{81}$ (Fig. 9, near-wake) the recirculation pattern is quite symmetric at site $\mathrm{N} 3\left(\theta\right.$ peaks at $\left.\pm 180^{\circ}\right)$, while it is absent in the Core case below $z / H_{81}=$ 0.5 , where the flow initially has a preferred channelling direction. Only at higher elevations do the histograms start to converge. While for the Core configuration at site N3 the instantaneous vertical velocity remains mostly positive up to $z / H_{81} \approx 0.7$, for the Tall set-up there are notable fractions of downdrafts at lower elevations that contribute to the overall low mean value, $W$ (Fig. 7a). This pattern is perhaps associated with vortex shedding from the roof of building $\mathrm{T}_{81}$, which affects the near-wake more strongly if the incident flow has lower turbulence intensity (Becker et al. 2002).

In the main wake of $\mathrm{T}_{81}$ (site N4), the occurrence frequency $P_{\theta}$ exhibits a distinct double peak in the Tall geometry. This pattern also occurs at site N5 (not shown) and may be linked to large vortices generated at the building sides, explaining the large amplitudes of $\overline{v^{\prime 2}}$ and hence $k$ (Fig. 8a). Huber (1988) used wind-tunnel flow experiments for isolated buildings to show that the length scales of such vortices in the wake centre are of the order of 1 to 2 times the building height. For the Core case, bimodal patterns of $P_{\theta}$ are absent; instead the histograms show mirrored tails between $z / H_{81}=0.45$ and 0.68 . Again this change in the wake structure can in part be related to the impact of smaller scale, less organized eddies created by the low-level canopy. The effect is to cascade the energy of large ('coherent') vortices down to smaller eddies that dissipate more quickly, which affects the intensity of vortex shedding (Khanduri et al. 1998).

Similar conclusions can be drawn for building T134 (Online Resource: Fig. ESM_5). Although the shapes of the two tall buildings are rather different, the flow response is very similar in terms of changes in flow recirculation and the bimodality of $P_{\theta}$, affecting the magnitude of $\overline{v^{\prime 2}}$. 


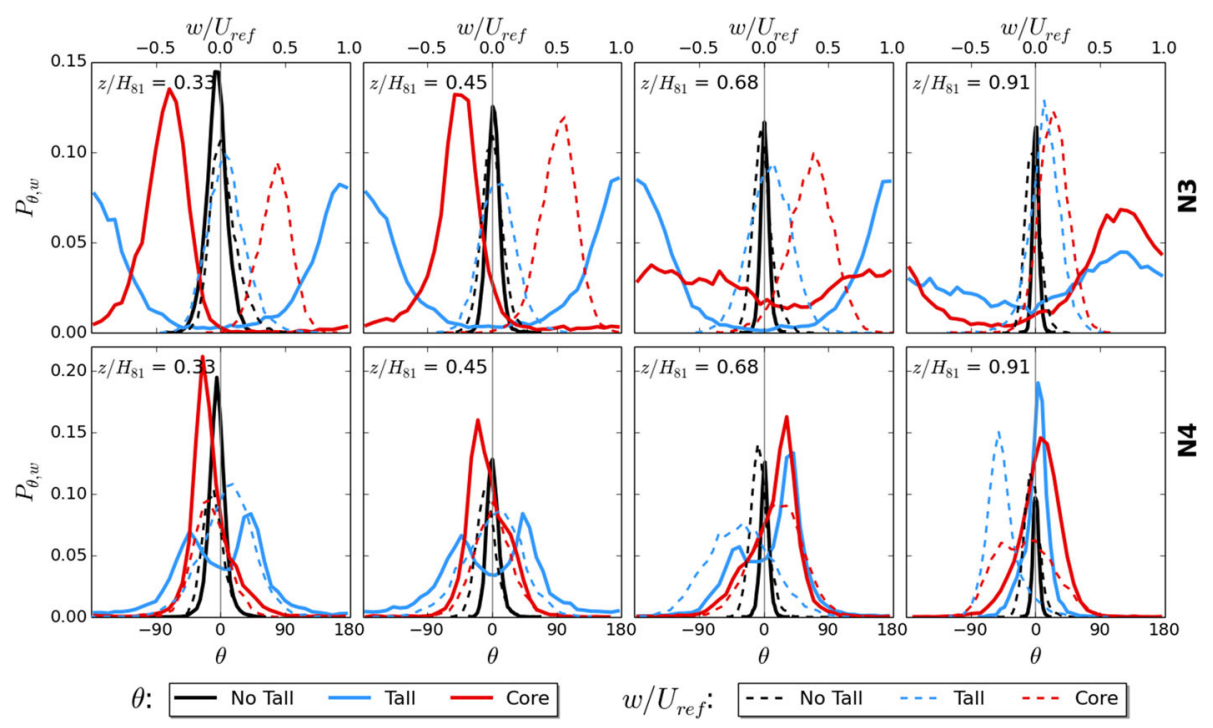

Fig. 9 Frequency distributions of instantaneous values of horizontal wind direction $\theta$ (solid lines) and vertical velocity $w$ (dashed lines) at sites N3 (near-wake) and N4 (main wake) downwind of building $\mathrm{T}_{81}$ (north orientation) at four heights for the No Tall, Tall and Core geometries

\subsection{Lateral Wake Characteristics}

The lateral structure of building $\mathrm{T}_{134}$ 's wake is investigated on three cross-wind transects (L1-L3) in the Core, Tall and No Tall configurations (Fig. 2d, e, f). Figure 10 shows the evolution of the velocity difference $\Delta U$ with lateral distance $\left(d_{y} / H_{134}\right)$ from the building centreline for Core-No Tall and Tall-BL-0. For the same sites, Fig. 11 shows lateral changes in the mean vertical velocity, $W$, in the Core and Tall geometries. The $x$ locations of transects L1 and L2 match those of the vertical profile sites S3 and S4, located in the near-wake and main wake. At transect L3, the near-wake of building $\mathrm{T}_{81}$ is overlapping with the main wake of $\mathrm{T}_{134}$. ADMS-Build model results are shown for the main-wake transect L2.

In both configurations the maximum velocity deficit at L1 is slightly offset from the building centreline at all heights as a result of the angle between the triangular tower $\mathrm{T}_{134}$ and the oncoming flow (Fig. 10a, b). At the downwind edge of the near-wake (transect L1), the variability of $\Delta U$ near the rooftop $\left(z / H_{134}=0.94\right.$ and 1$)$ confirms the large gradients in that flow region. At this height, $\Delta U$ in the Core and Tall cases shows distinct minima near the edges of the tower and rises towards the centre of the wake. This is accompanied by peaks of the velocity variances (Online Resource: Figs. ESM_6-8) and probably indicates the existence of counter-rotating vortices curling up from the building sides. The low spatial resolution of the $\mathrm{L} 3$ transect relative to the building width of building $\mathrm{T}_{81}$ does not permit to assess the existence of similar patterns for this case. Strong downdrafts near roof-level of building $\mathrm{T}_{134}$ (Fig. 11a, b) exist in both configurations, but in the near-wake of the Core set-up (L1 transect) downward flow is confined to the upper levels of the wake $\left(z / H_{134}>0.6\right)$, while in the lower half strong updrafts up to $0.4 U_{\text {ref }}$ exist. Updrafts are also enhanced in the near-wake of building $\mathrm{T}_{81}$ (Core case; Fig. 11e) by up to a factor of 4 compared the values in the Tall case (Fig. 11f) at $z / H_{81}=0.33$ and 0.8 . 

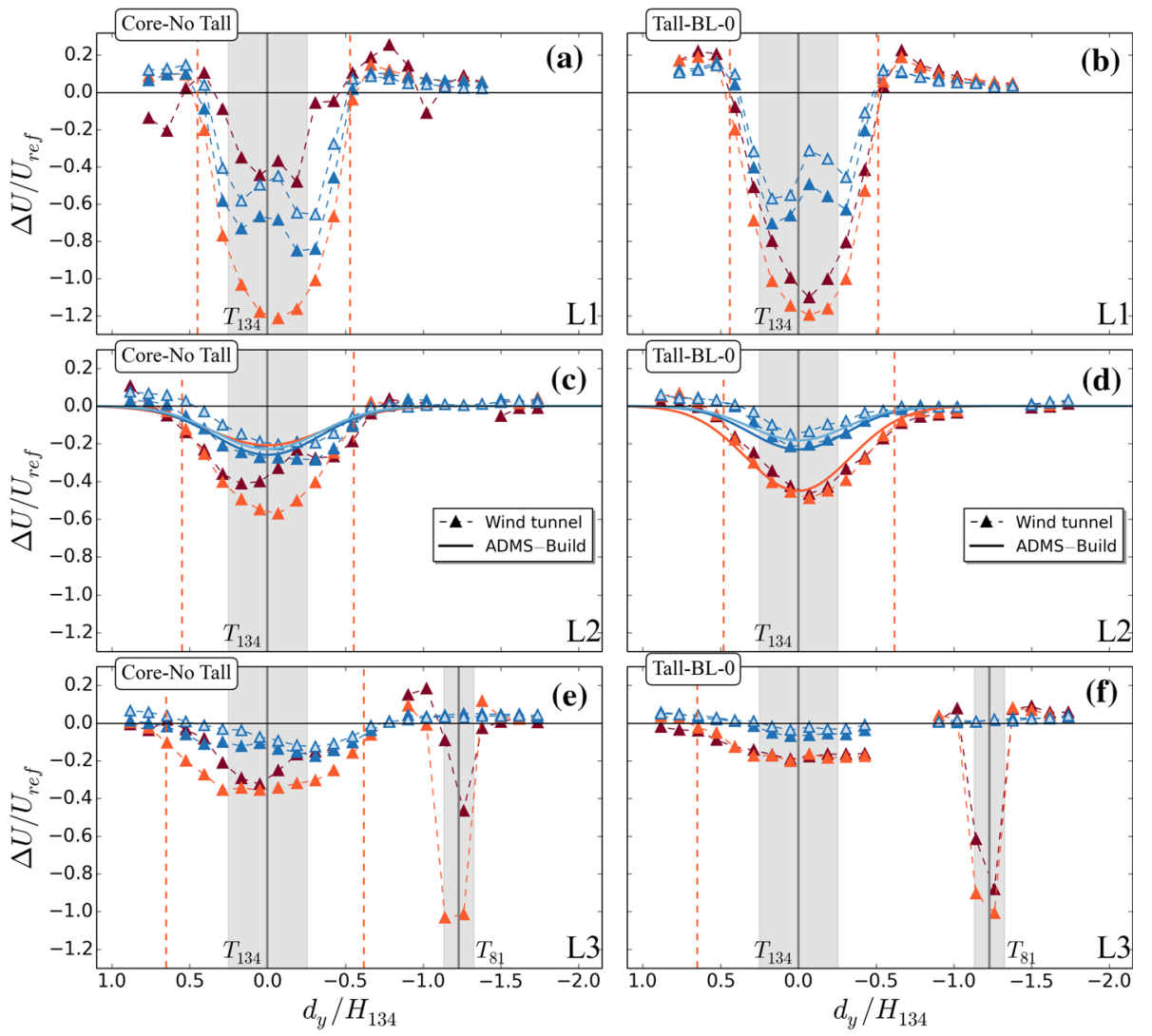

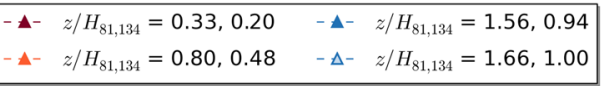

Fig. 10 Lateral profiles of the velocity deficit $\Delta U$ in the wake of building $\mathrm{T}_{134}$ for (a, c, e) Core-No Tall and b, d, f Tall-BL-0. Transects are located at $d_{x} / H_{134}=0.98,2.0$ and 2.86 (L1, L2, L3; Fig. 2f). Distances $d_{y} / H_{134}<0$ are for sites north of the building centreline. c, d ADMS-Build model results (thick solid lines) at transect L2. Vertical shading shows the width of the $\mathrm{T}_{134}$ and $\mathrm{T}_{81}$ buildings. Dashed vertical lines indicate where $\Delta U$ decreased below $10 \%$ of $U_{\text {ref }}$ at $z / H_{134}=0.48$ on either side of the wake

It is noticeable that the $W$ values at roof-level of building $\mathrm{T}_{134}$ do not converge back to the ambient $W \approx 0$, but remain negative on the $d_{y}>0$ side of the wake (Fig. 11). In the Core configuration this is also occurring at $z / H_{134}=0.48$. This asymmetry is likely a response to blockage effects and the corresponding pressure distribution around building $\mathrm{T}_{134}$, which is not aligned with the tunnel centreline (Fig 1d).

Close to the low-level canopy $\left(z / H_{134}=0.2\right)$, the Core-case transects show a superposition of wake characteristics of building $\mathrm{T}_{134}$ and local features of the RSL. On the L1 transect, for instance, the wake of a 30-m tall building located upwind (Fig. 2d) is captured at $d_{y} / H_{134}=-1$. The negative $\Delta U$ (Fig. 10a) indicates that the wake of this lower building is amplified by the presence of the tall building $\mathrm{T}_{134}$ compared to the No Tall reference state. Near the corners of $\mathrm{T}_{134}$ (Fig. 10b) and $\mathrm{T}_{81}$ (Fig. 10f) in the Tall set-up there is a speed-up of $U$ compared to the background state as the flow is deflected around the buildings. The presence of the urban canopy can locally enhance or reverse this feature, as seen on transect 


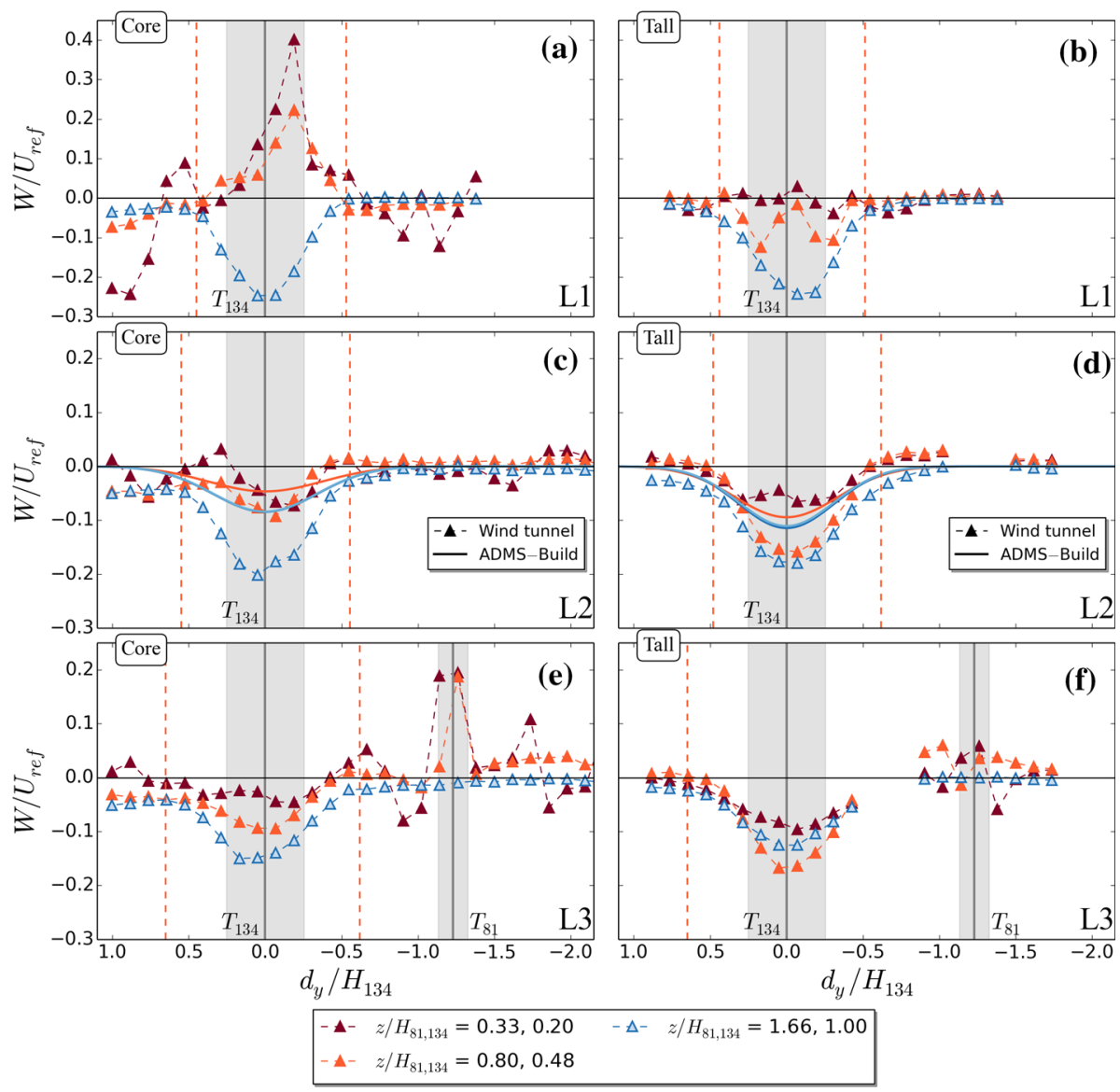

Fig. 11 As Fig. 10, but for the mean vertical velocity $W$ in the a, $\mathbf{c}, \mathbf{e}$ Core and $\mathbf{b}, \mathbf{d}, \mathbf{f}$ Tall cases

L1 on either side of building $\mathrm{T}_{134}$ (Fig. 10a; $z / H_{134}=0.2$ ) or on transect L3 near building $\mathrm{T}_{81}$ (Fig. 10e; $z / H_{81}=0.33$ ).

In the main wake of building $\mathrm{T}_{134}$ (transects L2/L3), the $\Delta U$ profiles in the Core and Tall configurations show the expected bell shape (e.g. Castro and Robins 1977) at sufficient distance from the low-level canopy. As in classic wake theory this is associated with a fast decay of the velocity deficit with $d_{y}$, accompanied by $W<0$. The magnitude of change of $\Delta U$ with $d_{y}$ decreases with height and with downwind distance $\left(d_{x}\right)$ from the tall building. The wake width, here defined as the extent of the region where the magnitude of $\Delta U$ is larger than $10 \%$ of $U_{r e f}$, for the Core/Tall geometries is $0.98 / 1.1 H_{134}$ (L1 transect), 1.1/1.27 $H_{134}$ (L2) and 1.27 $H_{134}$ (L3; Core case only). While the lateral growth of the wake is slightly greater in the Tall configuration, the magnitude of $\Delta U$ is enhanced in the Core case. When assessed through the disturbance of the velocity variances, the wake is noticeably wider below the rooftop of building $\mathrm{T}_{134}$ (up to a factor of 2 at $z / H_{134}=0.48$ in both configurations) compared to the mean-flow wake (Online Resource: Figs. ESM_6-8). Differences between the two geometries are more strongly reflected in the variances. The roof-level turbulence for tower $\mathrm{T}_{134}$ is enhanced over a wider lateral extent in the Core set- 
up, whereas below rooftop the variances show larger magnitudes in the isolated building case.

In the ADMS-Build wake model, similar to Eq. 1 but now at constant $z, \Delta U \propto e^{-y^{2} / x}$ (Eqs. 3, 7). Hence, $\Delta U \propto 1-y^{2} / x$ for $y^{2} / x \ll 1$, whereas for large $y^{2} / x$ the change in $\Delta U$ becomes slower and the profiles gradually converge back to the ambient flow. In between these limits, the lateral flow profiles exhibit a nearly linear portion $(\Delta U \propto y / x)$. Experimental and model results show very good agreement for the isolated building case (Fig. 10d) with respect to the overall magnitude of $\Delta U$ and the profile shape. Considering that the model does not reproduce the asymmetry of the wake caused by the oblique flow angle, the agreement between the wake widths is very good. While not capturing the magnitudes of $W$ well for this configuration, the model shows the same small vertical gradients in the Tall case as in the experiment (Fig. 11d). In agreement with the vertical flow structure in the Core set-up (Fig. 5a), $U$ is significantly overestimated at $z / H_{134}=0.48$, leading to a much smaller velocity deficit (Fig. 10c), while better predicted at roof-level. Similar conclusions can be drawn from the comparison of $W$ (Fig. 11c), where the model underestimates the increase of downdrafts with increasing height, resulting in larger differences at $z / H_{134}=1$ compared to 0.48 .

\section{Conclusions}

Current knowledge about building wakes, forming the basis of many empirical-analytical wake models, is mostly derived from flow past isolated structures in horizontally homogeneous turbulent boundary layers. However, the structure of the wake of tall buildings surrounded by a realistic urban canopy is different in many respects.

In this case study, the main changes in the wake flow structure in the canopy-interaction cases (Core/Increased) compared to the isolated building case (Tall) are:

\section{Changes in the Near-Wake (Core v Tall Configurations)}

- The sheltering effect of the low-level buildings in the Core geometries reduces $U$ values in the canopy and roughness sublayer, thereby limiting the vertical depth over which flow reversal occurs on the leeward side of the tall buildings and displacing the centre of the recirculation zone upwards. This creates larger shear $\left(\partial_{z} U\right)$ at the rooftop of the tall buildings and enhances velocity variances.

- Vertical momentum exchange $\left(-\overline{u^{\prime} w^{\prime}}\right)$ for the Core cases is enhanced by factors of 1.5 to 3 at rooftop of the tall buildings compared to Tall, and has a secondary peak at the top of the low-level canopy $\left(z=z_{0, K}+z_{d, K}\right)$, reducing the recirculation intensity in the near-wake.

- Above the low-level canopy, in the Core cases $U$ initially is positive over a depth of 0.1 to 0.2 times the tall-building height. Higher up, small-scale, diffusive eddies generated in the UCL and RSL reduce the strength of flow reversal over a large portion of the wake.

- Vertical velocities (e.g. updrafts on the leeward side of the tower in the near-wake) and horizontal flow directions above the canopy are strongly amplified in response to the local structure and orientation of the buildings and street systems underneath the wake. 


\section{Changes in the Main-Wake (Core v Tall Configurations)}

- The velocity difference $(\Delta U)$ relative to the ambient flow is amplified in the Core set-ups over the entire depth of the wake. Further increasing the building heights in the near-wake of the tower (Increased case), however, in the current scenario reduces $\Delta U$ as a result of strongly reduced flow reversal over larger portions of the near-wake and enhanced turbulent mixing downwind of the higher canopy.

- $\Delta U$ decays as $\left(d_{x} / H\right)^{-p}$, but for the Core cases the rate of decay (measured by $p$ ) varies more strongly with height and in response to the characteristics of the underlying roughness.

- The lateral wake extent based on the characteristics of $\Delta U$ and its growth with $d_{x} / H$ is similar in the Tall and Core geometries. For both, the classic relation of $\Delta U \propto e^{-y^{2} / x}$ used in the ADMS-Build wake model holds.

- At half the tall-building height $\left(\mathrm{T}_{134}\right)$, the turbulent wake is wider than the mean-flow wake by up to a factor of 2 (Tall and Core cases; Online Resource: Figs. ESM_6-8). Velocity variances at roof-level are enhanced over a larger lateral extent in the Core geometries, while below rooftop all variance components have larger magnitudes in the Tall cases.

- In the near part of the main wake, the bimodality in the frequency distributions of horizontal wind directions (likely associated with vortex shedding from the building sides) is suppressed in the Core cases. This is accompanied by a reduction of magnitudes of $\overline{v^{\prime 2}}$ and $k$ due to the down-scale transport of TKE to less-organized, smaller-scale canopy-layer eddies, which then dissipate more quickly.

- Turbulence integral time scales of the longitudinal velocity component associated with the energy containing eddies are reduced throughout the main wake in the Core scenarios.

While some of the changes in the wake behaviour are also observed for isolated tall buildings in boundary-layer flows with high turbulence intensity (e.g. reduction of recirculation intensity and vortex shedding), the interaction with mean flow and turbulence patterns generated in the low-level building canopy induces further structural changes of the wake on local to neighbourhood scales. The different flow response for Core SE $_{\text {and }}$ Increased $_{\mathrm{SE}}$ showed that very confined changes in the morphometric characteristics of the low-rise structures in the near-wake region of a tall building can have non-local effects, which need to be further investigated in configurations where the tall building is located in the centre of the domain (i.e. farther away from the model edge).

Comparisons with the ADMS-Build wake model showed that core modelling assumptions regarding the change of velocity with longitudinal and lateral distance from the tall building still are generally valid when the building is part of an urban canopy. However, the strong modifications of the vertical structure of the wake caused by the interaction with RSL and UCL turbulence cannot be accounted for by adjusting current model parameters (e.g. reducing the effective height of the building). It needs to be explored whether simple and generic model refinements can be made to capture such effects.

To achieve this, further investigations need to focus on the wake response to urban settings of different geometrical characteristics $\left(\lambda_{f}, \lambda_{p}\right)$ and building height variability $\left(\sigma_{H}\right)$, ideally also considering effects of atmospheric thermal stratification. Similarly, the interaction of wakes of tall buildings and the behaviour of wakes produced by building clusters need to be investigated in realistic urban settings. Understanding and quantifying tall building impacts on the inertial sublayer over cities (and above) is essential to identify needs for model refinements in urban land-surface models used in mesoscale and microscale atmospheric modelling as 
the increasing spatial resolution of such models $(\mathcal{O}(100 \mathrm{~m}))$ means that tall-building wakes no longer are subgrid-scale phenomena, but have an impact at the grid scale.

Acknowledgements The study was funded by NERC AirPro (NE/N00700X/1), EPSRC Refresh (EP/K021893/1) and EPSRC LoHCool (EP/N009797/1). Further funding (DH, SG) by the UK-China Research \& Innovation Partnership Fund through the Met Office Climate Science for Service Partnership (CSSP) China as part of the Newton Fund is gratefully acknowledged (High Res City; AJYG-DX4P1V). We thank partners in EPSRC MAGIC for the opportunity to carry out measurements using the MAGIC wind-tunnel model. We are grateful to Paul Nathan and Siu Hin Choi at EnFlo for their support during the measurement campaigns. Data published in this paper can be accessed at https://doi.org/10.5281/zenodo.2563700.

Open Access This article is distributed under the terms of the Creative Commons Attribution 4.0 International License (http://creativecommons.org/licenses/by/4.0/), which permits unrestricted use, distribution, and reproduction in any medium, provided you give appropriate credit to the original author(s) and the source, provide a link to the Creative Commons license, and indicate if changes were made.

\section{Appendix 1: ADMS-Build Wake Model}

Comparisons of observed wake characteristics are made with the ADMS-Build wake model (Robins et al. 2018) that is part of the urbanized version of the Gaussian plume-dispersion model ADMS (ADMS-Urban; Robins and McHugh 2001).

A small-deficit wake model represents the mean 3D flow structure in the momentum deficit region (main wake) of an isolated, cuboid-shaped building (Fig. 12). The model is applicable only where $U>0$, i.e. downwind of the near-wake cavity zone (recirculation region) where $x$ is larger than the cavity length $L_{R}$. The latter is determined from the height, cross-wind width and along-wind length $\left(H, W_{c}, L=L_{f}\right)$ of the building as

$$
L_{R}=\frac{A W_{c}}{1+B W_{c} / H}
$$

with $A=1.8(L / H)^{-0.3}$ and $B=0.24$. If $L / H<0.3$ then $A=2.58$ and if $L / H>3.0$ then $A=1.3$. Note that if $W_{c} / H$ is small, $L_{R} \approx A W_{c}$.

The model is a 3D extension of the original 2D model of Counihan et al. (1974) and based on constant eddy-viscosity wake theory. The mean flow components are

$$
\begin{aligned}
U & =U_{H}\left[1-\hat{u}\left(\frac{W_{c}}{2 \ell_{y}}\right)\left(\frac{H}{\ell_{z}}\right)^{2} g(\xi) h(\eta)\right], \\
V & =-U_{H} \hat{u}\left(\frac{W_{c}}{2\left(x-x_{0}\right)}\right)\left(\frac{H}{\ell_{z}}\right)^{2} g(\xi) \frac{\eta}{2} h(\eta), \\
W & =-U_{H} \hat{u}\left(\frac{H}{\left(x-x_{0}\right)}\right)\left(\frac{W_{c}}{2 \ell_{y}}\right)\left(\frac{H}{\ell_{z}}\right)\left[g^{\prime}(0)-g^{\prime}(\xi)\right] h(\eta),
\end{aligned}
$$

where $U_{H}$ is the mean longitudinal velocity component of the ambient flow at roof-level $(z=H)$ and $g^{\prime}$ in Eq. 5 denotes a derivative with respect to $\xi$. To match the inflow conditions of the wind tunnel, we use vertically-varying inflow profiles $U(z)$ in Eqs. 3-5. For the Tall $\mathrm{N}_{\mathrm{S}} \mathrm{SE}$ cases, the inflow is given by $U(z)$ in the approach flow (BL-0), while for the Core $\mathrm{N}_{\mathrm{SE}}$ geometries $U(z)$ is given by the No Tall $\mathrm{N}_{\mathrm{N} \text { SE }}$ profiles (Fig. 3a). 


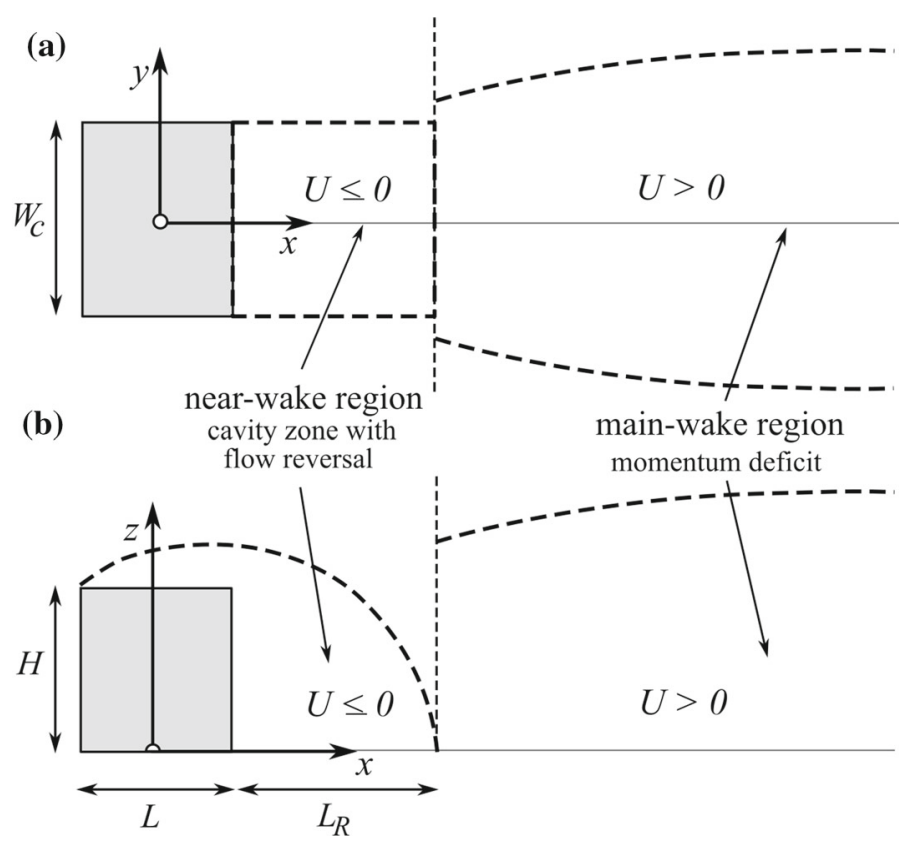

Fig. 12 Near-wake and main-wake flow regions in the ADMS-Build model in a the $x-y$ plane and $\mathbf{b} x-z$ plane. Adapted from Robins et al. (2018)

The normalized cross-wind dimensions are $\eta=y / \ell_{y}$ and $\xi=z / \ell_{z}$, with the length scales being a function of longitudinal distance,

$$
\ell_{y, z}(x)=\sqrt{\frac{D_{y, z}\left(x-x_{0}\right)}{U_{H}}},
$$

where $D_{y}=\kappa u_{*} H$ and $D_{z}=2 \kappa u_{*} H$ are expressions for the constant eddy viscosities under neutral conditions. For the Tall cases, $u_{*}=0.11 \mathrm{~m} \mathrm{~s}^{-1}$ of the BL-0 configuration is used (Sect. 3.3). For the No Tall configurations, $u_{*}$ is derived from the peak value of the vertical turbulent momentum flux in the RSL (Fig. 3b); resulting in $u_{*}=0.14 \mathrm{~m} \mathrm{~s}^{-1}$ (north orientation) and $0.16 \mathrm{~m} \mathrm{~s}^{-1}$ (south-east). In the Core set-ups, the building height $H$ is set to $H_{\text {eff }}$ (Table 4). The virtual origin $x_{0}$ used in Eq. 6 is specified so that $U>0$ throughout the main wake. The dimensionless velocity perturbation parameter $\hat{u}$ is set to the default model value of 0.45 .

The shape functions $g(\xi)$ and $h(\eta)$ used in Eqs. 3-5 are defined as

$$
g(\xi)=\frac{\xi}{2} \exp \left(-\frac{\xi^{2}}{4}\right) \text { and } h(\eta)=\frac{1}{2 \sqrt{\pi}} \exp \left(-\frac{\eta^{2}}{4}\right) \text {. }
$$

\section{Appendix 2: Approach-Flow Characteristics}

To characterize the boundary-layer flow upwind of the model (BL-0), vertical profiles of mean flow (Fig. 13a) and turbulence statistics (Figs. 13b, c and 14) were analyzed just after the last row of roughness elements (Table 5 and Sect. 3.3). The data are spatially-averaged 
(a)

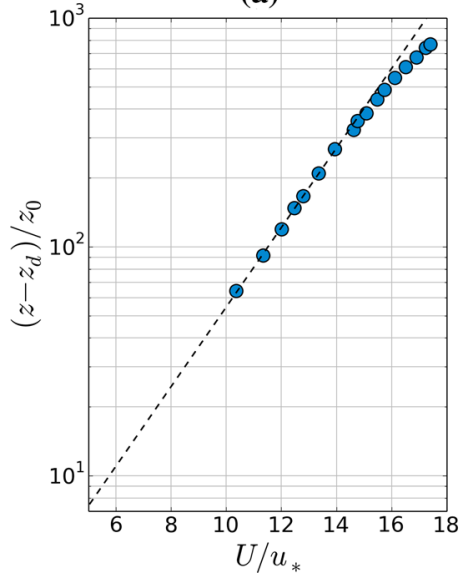

(b)

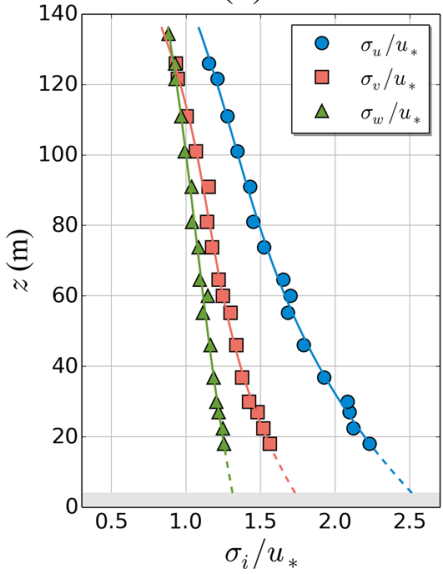

(c)

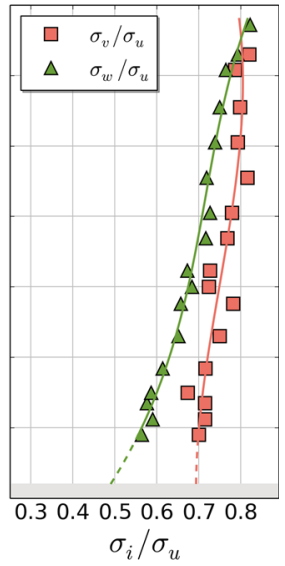

Fig. 13 Approach-flow profiles (BL- -0 case) of a mean longitudinal velocity $U$, b turbulence intensities $\left(\sigma_{i}\right)$ scaled by $u_{*}$, and $\mathbf{c}$ ratios of turbulence intensities. Solid lines in $\mathbf{b}, \mathbf{c}$ show a polynomial fit of the profiles with an extrapolation to the height of the roughness elements (dashed line). Shading indicates the height of the floor-roughness elements

(a)

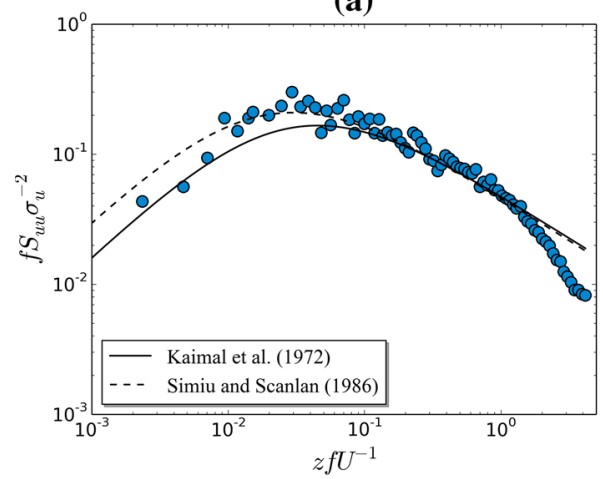

(b)

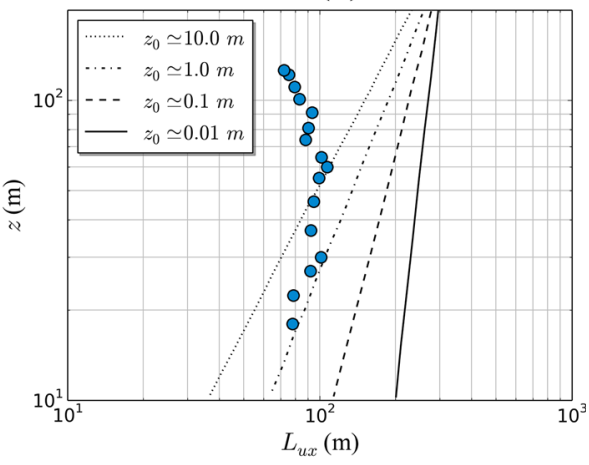

Fig. 14 a 1D energy-density spectrum of the longitudinal velocity component in the frequency $(f)$ domain at $z=27 \mathrm{~m}$ for the BL-0 case together with empirical relations (Kaimal et al. 1972; Simiu and Scanlan 1986). b Vertical profile of integral length scales in the $x$ direction associated with the $u$-component in the BL-0 case together with Counihan's (1975) empirical margins for different roughness regimes

time-mean statistics over three vertical profiles taken at $y=-600 \mathrm{~mm}, 0,+600 \mathrm{~mm}$ (windtunnel scale).

Mean flow and turbulence statistics (Fig. 13) show typical ISL characteristics in the region $9 \mathrm{~m} \leq z \leq 60 \mathrm{~m}$. The ratios of turbulence intensity $\sigma_{i}={\overline{u_{i}^{2}}}^{1 / 2}$ to friction velocity $\left(\sigma_{i} / u_{*}\right)$ approach values of 2.5, 1.73 and 1.3 for fluctuations of $u, v$ and $w$ above the roughness elements (Fig. 13b), in agreement with the classic Counihan (1975) relations. The ratios of velocity fluctuations approach values of $\sigma_{v} / \sigma_{u}=0.7$ and $\sigma_{w} / \sigma_{u}=0.49$ (Fig. 13c).

Based on the aerodynamic roughness parameters and turbulence intensities, the approach flow is consistent with moderately rough surface conditions based on the roughness regimes defined in the ESDU (1985) and VDI (2000) wind-tunnel modelling guidelines. Eddy statis- 
Table 5 Overview of the flow and roughness characteristics in the BL- 0 configuration. All values are given in full-scale for a reference wind speed $U_{\text {ref }}=2 \mathrm{~m} \mathrm{~s}^{-1}$

\begin{tabular}{llllll}
\hline Roughness & $u_{*}\left(\mathrm{~m} \mathrm{~s}^{-1}\right)$ & $z_{0}(\mathrm{~m})$ & $z_{d}(\mathrm{~m})$ & $\kappa$ & \\
& 0.11 & 0.16 & 3.4 & 0.4 & \\
Turbulence & $\sigma_{u} / u_{*}$ & $\sigma_{v} / u_{*}$ & $\sigma_{w} / u_{*}$ & $\sigma_{v} / \sigma_{u}$ & $\sigma_{w} / \sigma_{u}$ \\
& 2.5 & 1.75 & 1.3 & 0.7 & 0.49 \\
Depths & $\delta_{B L-0}(\mathrm{~m})$ & $\delta_{I S L}(\mathrm{~m})$ & & & \\
& 134 & 51 & & & \\
& & & & & \\
\hline
\end{tabular}

tics in terms of the energy-density spectrum (Fig. 14a) and integral length scales (Fig. 14b) support this assessment and agree well with empirical relations. The energy spectrum shows the characteristic rate of decay in the inertial sub-range and a well-established energy peak at a dimensionless frequency of $z f U^{-1} \approx 0.03$.

The turbulence integral length scales $\left(L_{u x}\right)$ in the longitudinal direction were determined from the integral time scales, $\tau_{u}$, associated with the $u$-component, using Taylor's frozen turbulence assumption: $L_{u x}=\tau_{u} U$. In the ISL, $L_{u x}$ falls within the empirically determined regime envelope for a moderately rough boundary layer in agreement with turbulence and mean-flow parameters, showing that a physically consistent boundary-layer flow was modelled.

\section{References}

Barlow J, Best M, Bohnenstengel SI, Clark P, Grimmond S, Lean H et al (2017) Developing a research strategy to better understand, observe and simulate urban atmospheric processes at kilometre to sub-kilometre scales. Bull Am Meteorol Soc 98:ES261-ES264. https://doi.org/10.1175/BAMS-D-17-0106.1

Becker S, Lienhart H, Durst F (2002) Flow around three-dimensional obstacles in boundary layers. J Wind Eng Ind Aerodyn 90(4):265-279. https://doi.org/10.1016/S0167-6105(01)00209-4

Blocken B, Carmeliet J (2004) Pedestrian wind environment around buildings: literature review and practical examples. J Thermal Envel Build Sci 28(2):107-159. https://doi.org/10.1177/1097196304044396

Blocken B, Janssen WD, van Hooff T (2012) CFD simulation for pedestrian wind comfort and wind safety in urban areas: general decision framework and case study for the Eindhoven University campus. Environ Modell Softw 30:15-34. https://doi.org/10.1016/j.envsoft.2011.11.009

Brixey LA, Heist DK, Richmond-Bryant J, Bowker GE, Perry SG, Wiener RW (2009) The effect of a tall tower on flow and dispersion through a model urban neighborhood: Part 2. Pollutant dispersion. J Environ Monitor 11(12):2171-2179. https://doi.org/10.1039/b907137g

Castro IP, Robins AG (1977) The flow around a surface-mounted cube in uniform and turbulent streams. J Fluid Mech 79(2):307-335. https://doi.org/10.1017/S0022112077000172

Coceal O, Belcher SE (2004) A canopy model of mean winds through urban areas. Q J Roy Meteorol Soc 130(599):1349-1372. https://doi.org/10.1256/qj.03.40

Counihan J (1975) Adiabatic atmospheric boundary layers: a review and analysis of data from the period 1880-1972. Atmos Environ (1967) 9(10):871-905. https://doi.org/10.1016/0004-6981(75)90088-8

Counihan J, Hunt JCR, Jackson PS (1974) Wakes behind two-dimensional surface obstacles in turbulent boundary layers. J Fluid Mech 64(3):529-563. https://doi.org/10.1017/S0022112074002539

Daniels SJ, Castro IP, Xie ZT (2013) Peak loading and surface pressure fluctuations of a tall model building. J Wind Eng Ind Aerodyn 120:19-28. https://doi.org/10.1016/J.JWEIA.2013.06.014

Elshaer A, Aboshosha H, Bitsuamlak G, El Damatty A, Dagnew A (2016) LES evaluation of wind-induced responses for an isolated and a surrounded tall building. Eng Struct 115:179-195. https://doi.org/10. 1016/J.ENGSTRUCT.2016.02.026

ESDU (1985) Characteristics of atmospheric turbulence near the ground. Part II: single point data for strong winds (neutral atmosphere). Engineering Sciences Data Unit, London, UK, ESDU 85020

Fackrell J (1984) Parameters characterising dispersion in the near wake of buildings. J Wind Eng Ind Aerodyn 16(1):97-118. https://doi.org/10.1016/0167-6105(84)90051-5 
Fuka V, Xie ZT, Castro IP, Hayden P, Carpentieri M, Robins AG (2018) Scalar fluxes near a tall building in an aligned array of rectangular buildings. Boundary-Layer Meteorol 167(1):53-76. https://doi.org/10. 1007/s10546-017-0308-4

Grimmond CSB, Blackett M, Best MJ, Barlow J, Baik JJ, Belcher SE, Bohnenstengel SI et al (2010) The international urban energy balance models comparison project: first results from phase 1. J Appl Meteorol Clim 49(6):1268-1292. https://doi.org/10.1175/2010JAMC2354.1

Heist DK, Brixey LA, Richmond-Bryant J, Bowker GE, Perry SG, Wiener RW (2009) The effect of a tall tower on flow and dispersion through a model urban neighborhood: Part 1. Flow characteristics. J Environ Monitor 11(12):2163-2170. https://doi.org/10.1039/b907135k

Holmes JD (2014) Along- and cross-wind response of a generic tall building: comparison of wind-tunnel data with codes and standards. J Wind Eng Ind Aerodyn 132:136-141. https://doi.org/10.1016/J.JWEIA. 2014.06.022

Hosker RP (1983) Methods for estimating wake flow and effluent dispersion near simple block-like buildings. National Oceanic and Atmospheric Administration, Silver Spring, MD (USA). Air Resources Lab., NOAA-TM-ERL-ARL-108. https://doi.org/10.2172/5359876

Huber AH (1988) Video images of smoke dispersion in the near wake of a model building. Part I. Temporal and spatial scales of vortex shedding. J Wind Eng Ind Aerodyn 31(2):189-224. https://doi.org/10.1016/ 0167-6105(88)90004-9

Hunt JCR (1971) The effect of single buildings and structures. Philos Trans R Soc Lond A 269(1199):457-467. https://doi.org/10.1098/rsta.1971.0044

Hunt JCR, Abell CJ, Peterka JA, Woo H (1978) Kinematical studies of the flows around free or surfacemounted obstacles; applying topology to flow visualization. J Fluid Mech 86(1):179-200. https://doi. org/10.1017/S0022112078001068

Hussain M, Lee B (1980) A wind tunnel study of the mean pressure forces acting on large groups of low-rise buildings. J Wind Eng Ind Aerodyn 6(3-4):207-225. https://doi.org/10.1016/0167-6105(80)90002-1

Kaimal JC, Wyngaard JC, Izumi Y, Cot OR (1972) Spectral characteristics of surface-layer turbulence. Q J Roy Meteorol Soc 98(417):563-589. https://doi.org/10.1002/qj.49709841707

Kanda M, Inagaki A, Miyamoto T, Gryschka M, Raasch S (2013) A new aerodynamic parametrization for real urban surfaces. Boundary-Layer Meteorol 148(2):357-377. https://doi.org/10.1007/s10546-0139818-x

Kent CW, Grimmond S, Barlow J, Gatey D, Kotthaus S, Lindberg F, Halios CH (2017) Evaluation of urban local-scale aerodynamic parameters: implications for the vertical profile of wind speed and for source areas. Boundary-Layer Meteorol 164(2):183-213. https://doi.org/10.1007/s10546-017-0248-z

Kent CW, Grimmond C, Gatey D, Barlow JF (2018) Assessing methods to extrapolate the vertical windspeed profile from surface observations in a city centre during strong winds. J Wind Eng Ind Aerodyn 173:100-111. https://doi.org/10.1016/J.JWEIA.2017.09.007

Khanduri AC, Stathopoulos T, Bédard C (1998) Wind-induced interference effects on buildings—a review of the state-of-the-art. Eng Struct 20(7):617-630. https://doi.org/10.1016/S0141-0296(97)00066-7

Kwon DK, Kareem A (2013) Comparative study of major international wind codes and standards for wind effects on tall buildings. Eng Struct 51:23-35. https://doi.org/10.1016/j.engstruct.2013.01.008

Le TH, Caracoglia L (2016) Modeling vortex-shedding effects for the stochastic response of tall buildings in non-synoptic winds. J Fluid Struct 61:461-491. https://doi.org/10.1016/j.jfluidstructs.2015.12.006

Li Q, Fu J, Xiao Y, Li Z, Ni Z, Xie Z, Gu M (2006) Wind tunnel and full-scale study of wind effects on China's tallest building. Eng Struct 28(12):1745-1758. https://doi.org/10.1016/j.engstruct.2006.02.017

Li Q, Xiao Y, Fu J, Li Z (2007) Full-scale measurements of wind effects on the Jin Mao building. J Wind Eng Ind Aerodyn 95(6):445-466. https://doi.org/10.1016/j.jweia.2006.09.002

Lim HC, Thomas TG, Castro IP (2009) Flow around a cube in a turbulent boundary layer: LES and experiment. J Wind Eng Ind Aerodyn 97(2):96-109. https://doi.org/10.1016/j.jweia.2009.01.001

Masson V (2000) A physically-based scheme for the urban energy budget in atmospheric models. BoundaryLayer Meteorol 94(3):357-397. https://doi.org/10.1023/A:1002463829265

$\mathrm{Ng}$ E (2009) Policies and technical guidelines for urban planning of high-density cities — air ventilation assessment (AVA) of Hong Kong. Build Environ 44(7):1478-1488. https://doi.org/10.1016/J.BUILDENV. 2008.06.013

Ogawa Y, Oikawa S, Uehara K (1983) Field and wind tunnel study of the flow and diffusion around a model cube-I. Flow measurements. Atmos Environ (1967) 17(6):1145-1159. https://doi.org/10.1016/00046981(83)90338-4

Oke TR (1988) Street design and urban canopy layer climate. Energ Build 11(1-3):103-113. https://doi.org/ 10.1016/0378-7788(88)90026-6

Pardyjak ER, Brown MJ, Bagal NL (2004) Improved velocity deficit parameterizations for a fast response urban wind model. In: Proceedings of the 84th AMS annual meeting, Seattle (WA) 
Petersen RL, Guerra SA, Bova AS (2017) Critical review of the building downwash algorithms in AERMOD. J Air Waste Manag 67(8):826-835. https://doi.org/10.1080/10962247.2017.1279088

Robins A, McHugh C (2001) Development and evaluation of the ADMS building effects module. Int J Environ Pollut 16:161-174. https://doi.org/10.1504/IJEP.2001.000614

Robins AG, Apsely DD et al (2018) Modelling building effects in ADMS. CERC, Tech Rep P16/01W/18

Simiu E, Scanlan RH (1986) Wind effects on structures, 2nd edn. Wiley, Hoboken

Singh B, Pardyjak ER, Brown MJ (2006) Testing of a far-wake parameterization for a fast response urban wind model. In: Proceedings of the 6th symposium on the urban environment, Atlanta (GA)

Song J, Fan S, Lin W, Mottet L, Wooward H, Davies Wykes M et al (2018) Natural ventilation in cities: the implications of fluid mechanics. Build Res Inf 46(8):809-828. https://doi.org/10.1080/09613218.2018. 1468158

Tominaga Y, Mochida A, Yoshie R, Kataoka H, Nozu T, Yoshikawa M, Shirasawa T (2008) AIJ guidelines for practical applications of CFD to pedestrian wind environment around buildings. J Wind Eng Ind Aerodyn 96(10-11):1749-1761. https://doi.org/10.1016/j.jweia.2008.02.058

VDI (2000) Environmental meteorology. Physical modelling of flow and dispersion processes in the atmospheric boundary layer, Application of wind tunnels. Verein Deutscher Ingenieure, Beuth Verlag, Berlin, VDI 3783-12

Wardlaw RL, Moss GF (1970) A standard tall building model for the comparison of simulated natural winds in wind tunnels. CAARC, CC $662 \mathrm{~m}$ Tech 25

Wyngaard JC (1992) Atmospheric turbulence. Annu Rev Fluid Mech 24(1):205-234. https://doi.org/10.1146/ annurev.fl.24.010192.001225

Xu X, Yang Q, Yoshida A, Tamura Y (2017) Characteristics of pedestrian-level wind around super-tall buildings with various configurations. J Wind Eng Ind Aerodyn 166:61-73. https://doi.org/10.1016/j.jweia.2017. 03.013

Yang F, Lau SS, Qian F (2010) Summertime heat island intensities in three high-rise housing quarters in inner-city Shanghai China: building layout, density and greenery. Build Environ 45(1):115-134. https:// doi.org/10.1016/j.buildenv.2009.05.010

Yang X, Li Y (2015) The impact of building density and building height heterogeneity on average urban albedo and street surface temperature. Build Environ 90:146-156. https://doi.org/10.1016/j.buildenv.2015.03. 037

Publisher's Note Springer Nature remains neutral with regard to jurisdictional claims in published maps and institutional affiliations. 